\title{
Green Biocomposites for Thermoelectric Wearable Applications
}

\section{DOI:}

10.1002/adfm.201907301

\section{Document Version}

Accepted author manuscript

Link to publication record in Manchester Research Explorer

\section{Citation for published version (APA):}

Cataldi, P., Cassinelli, M., Heredia-Guerrero, J. A., Guzman-Puyol, S., Naderizadeh, S., Athanassiou, A., \& Caironi, M. (2020). Green Biocomposites for Thermoelectric Wearable Applications. Advanced Functional Materials, 30(3), [1907301]. https://doi.org/10.1002/adfm.201907301

\section{Published in:}

Advanced Functional Materials

\section{Citing this paper}

Please note that where the full-text provided on Manchester Research Explorer is the Author Accepted Manuscript or Proof version this may differ from the final Published version. If citing, it is advised that you check and use the publisher's definitive version.

\section{General rights}

Copyright and moral rights for the publications made accessible in the Research Explorer are retained by the authors and/or other copyright owners and it is a condition of accessing publications that users recognise and abide by the legal requirements associated with these rights.

\section{Takedown policy}

If you believe that this document breaches copyright please refer to the University of Manchester's Takedown Procedures [http://man.ac.uk/04Y6Bo] or contact uml.scholarlycommunications@manchester.ac.uk providing relevant details, so we can investigate your claim.

\section{OPEN ACCESS}




\section{WILEY-VCH}

DOI: 10.1002/ ((please add manuscript number))

Article type: Article

\section{Green Biocomposites for Thermoelectric Wearable Applications}

Pietro Cataldi* and Marco Cassinelli, José A. Heredia-Guerrero, Susana Guzman-Puyol, Sara Naderizadeh, Athanassia Athanassiou, and Mario Caironi*

(P. Cataldi and M. Cassinelli contributed equally and are both first authors)

Dr. P. Cataldi, Dr. J.A. Heredia-Guerrero, Dr. S. Guzman-Puyol, S. Naderizadeh, Dr. A. Athanassiou

Smart Materials, Istituto Italiano di Tecnologia

Via Morego 30, 16163 Genova, Italy.

Email: pietro.cataldi@manchester.ac.uk

Dr. M. Cassinelli, Dr. M. Caironi

Center for Nano Science and Technology @PoliMi, Istituto Italiano di Tecnologia

Via Pascoli 70/3, Milano 20133, Italy.

Email: mario.caironi@iit.it

Present Addresses

$\dagger$ National Graphene Institute, University of Manchester, Booth Street East, Manchester M13 9PL, United Kingdom

Keywords: organic thermoelectrics, carbon nanotubes, graphene nanoplatelets, $n$-type thermoelectric materials, sustainable thermoelectric, carbon nanofibers

Nowadays, the materials commonly used to fabricate thermoelectric devices are tellurium, lead and germanium. These materials ensure from one side the best thermoelectric performances, but exhibit drawbacks in terms of availability, sustainability, cost and manufacturing complexity. Moreover, they do not guarantee a safe and cheap implementation in wearable thermoelectric applications. Here, $p$ - and $n$-type flexible thermoelectric textiles are produced with sustainable and low-cost materials through green and scalable processes. Cotton is functionalized with inks made with biopolyester and carbon-nanomaterials. Depending on the nanofiller, i.e. graphene nanoplatelets, carbon nanotubes or carbon nanofibers, positive or negative Seebeck coefficient values are obtained, achieving also a remarkable value of electrical conductivity of $55 \mathrm{~S} \mathrm{~cm}^{-1}$ using carbon nanotubes. The best bending and washing stability are registered for the carbon nanofibers-based biocomposites, which increase their electrical resistance by 5 times after repeated bending cycles and only of the $30 \%$ after washing. Finally, in-plane flexible thermoelectric generators are fabricated and characterized coupling the best $p$ - and $n$-type materials, achieving an output voltage of $\sim 1.65$ $\mathrm{mV}$ and a maximum output power of $\sim 1.0 \mathrm{nW}$ by connecting only $2 \mathrm{p} / \mathrm{n}$ thermocouples at a temperature difference of $70^{\circ} \mathrm{C}$. 


\section{WILEY-VCH}

1. Introduction

Wearable technologies are forecasted to branch out abruptly in next years through the diffusion of smart textiles and the internet-of-things, reaching a $\sim 46$ billion $€$ market by 2022. ${ }^{[1-3]}$ Electronic textiles (e-textiles) are an interesting platform for a wide range of applications ranging from medical care ${ }^{[2,4]}$ to energy harvesting and storage. ${ }^{[1,5-7]}$ The thermoelectric (TE) effect allows energy harvesting through the so-called Seebeck effect, exploiting solely a temperature gradient, ${ }^{[8-12]}$ for example, between the human body and the usually colder surroundings. ${ }^{[13,14]}$ Conversely, TE textiles can also be used as on-the-spot body cooler by the incorporation into sportswear, office chairs or car seats. ${ }^{[12-17]}$ Currently, the most performant thermoelectric generators (TEGs) are rigid devices based on toxic and expensive inorganic materials, ${ }^{[5,18-30]}$ and, hence, not suitable for wearing and mobile applications. ${ }^{[5,6,31]}$ Consequently, there is a massive interest in fabricating flexible and wearable TE materials based on doped organic semiconductor materials. ${ }^{[5,18-24,31]}$ To develop a textile-based TEG, both $p$ - and $n$-type textile materials are needed. In literature, TE organic p-type textile materials are already reported, using for example the conductive poly $(3,4-$

ehtylenedioxythiophene):poly(styrenesulfonate) (PEDOT:PSS), and carbon nanotubes. ${ }^{[15,32-34]}$ On the other hand, reports of $n$-type organic textiles are rare due to the lack of air-stable $n$ type organic semiconductor materials. ${ }^{[35]}$ Notable examples are the works of Ito et al.,${ }^{[36]}$ demonstrating the fabrication of doped carbon nanotubes fibers with switchable $p$ - and $n$-type behavior, and of Ryan et al., ${ }^{[21]}$ reporting the fabrication of $n$-type yarns by coating commercial poly(ethylene terephthalate) (PET) with a composite of carbon nanotubes and poly( $N$-vinylpyrrolidone) (PVP). This absence of $n$-type available materials forced the construction of inefficient TEG modules, obtained by replacing the $n$-type legs with metallic (e.g. silver) interconnections. ${ }^{[15,32,33,37,38]}$ In this sense, the development of $n$-type textiles is the current challenge for a further boost of wearable TE generators. 


\section{WILEY-VCH}

One of the principal building blocks for wearable technologies is cotton due to its natural origin, lightweight, fast biodegradability and large-scale availability. ${ }^{[39-41]}$ Common methods for the realization of wearable devices rely on the functionalization of cotton substrates with different nanoparticles depending on the properties required for the target applications. ${ }^{[39-43]}$ This approach disclosed important developments in the field of TE materials as well. ${ }^{[31,44]}$ Indeed, nanoparticles and nanostructures demonstrated a high potential to revolutionize TE materials increasing their efficiency. ${ }^{[18,45-49]}$

Among nanostructured materials, large-scale available carbon-based nanofillers, e.g., graphene nanoplatelets (GnPs), carbon nanofibers ( $\mathrm{CnFs})$, and multiwalled carbon nanotubes (CnTs), have been reported to be beneficial in a range of applications such as flexible ${ }^{[43,50-60]}$ and wearable ${ }^{[39,61]}$ electronics, composites for thermal management ${ }^{[62,63]}$, electrodiagnostic ${ }^{[64,}$ ${ }^{65]}$, structural reinforcement ${ }^{[52,63,66,67]}$, gas barrier ${ }^{[68]}$, solar cells ${ }^{[69-71]}$, electromagnetic interference shielding ${ }^{[53,64,72]}$ and robotics ${ }^{[51,73]}$. Similarly, an increased interest in using these carbon-based nanomaterials has been also reported for TE applications, ${ }^{[24,33,74-77]}$ even coupled to textile materials $^{[20,21,34,36,37,48,78,79]}$ to fabricate fully-organic and wearable TE materials. ${ }^{[12,35,44,80-93]}$

Among other organic and sustainable materials, aleuritic (9,10,16-trihydroxyhexadecanoic) acid has been employed as a building block of polymers that mimics the main structural component of the plant cutin (the most common polyester in nature). ${ }^{[94]}$ It is isolated from shellac, a natural lac resin produced by secretion of female Kerria lacca bugs on the branches of several host trees mainly from India and Thailand. ${ }^{[95]}$ Usually, this polyhydroxylated fatty acid is self-polymerized by melt-polycondensation or other chemical approaches to produce polyaleuritate, a long-chain polyester with interesting properties such as good hydrophobicity, infusibility, insolubility and full biodegradability. ${ }^{[95-99]}$ Aleuritic acid has been also combined with cellulose $\mathrm{e}^{[100]}$ and lactid acid ${ }^{[101]}$ at different ratios to tune the mechanical and barrier 


\section{WILEY-VCH}

properties of the resultant polymers blend. In general, the main applications of polyaleuritate are related to the fabrication of composites for food packaging ${ }^{[102]}$ and electronics ${ }^{[53]}$. In this work, sustainable, fully organic and flexible TE materials were produced through highly scalable and green processes. For this, cotton was sprayed with TE inks prepared by mixing carbon nanomaterials, including $\mathrm{CnFs}$, GnPs and $\mathrm{CnTs}$, and aleuritic acid in waterethanol. The subsequent cross-linking of aleuritic acid into polyaleuritate bound the nanofillers with the substrate. Biodegradability of the resultant biocomposites was characterized in seawater by biological oxygen demand (BOD) tests and the stability of the electrical properties to bending and washing cycles was found to be dependent on the kind of nanofiller employed, with the CnFs-based samples showing the best performances. The Seebeck coefficient was found to be tunable from positive values, characteristic of $p$-type TE materials, using GnPs and $\mathrm{CnFs}$, to negative values, characterizing $n$-type TE materials, using CnTs. Moreover, adding PEDOT:PSS to the $p$-type inks enhanced the Seebeck coefficient of the materials and decreased the sheet resistance, leading to better performing TE materials. Finally, by coupling $p$ - and $n$-type thermoelectric legs based on the proposed TE materials, a proof-of-concept, in-plane flexible TEG was fabricated and characterized.

\section{Results and Discussion}

The different inks were prepared by mixing same volumes of water and ethanol to disperse aleuritic acid and carbon-based nanofillers, as shown in Figure 1a. The ink formulation was optimized employing a concentration of $15 \mathrm{mg} \mathrm{mL}^{-1}$ of aleuritic acid and adding different amounts of nanofillers, ranging from 10 to $80 \mathrm{wt}$. \% with respect to the dry polymer. In the case of CnTs-based ink, an extra amount of PVP equal to the weight of the carbon nanofiller was added to the ink formulation. Such formulation were previously reported to lead to a negative Seebeck coefficient of the material. ${ }^{[103]}$ The nomenclature of the samples is reported in Table 1 and Table S1. Different features of the fillers GnPs, CnFs and CnTs, such as 


\section{WILEY-VCH}

particles size and Raman spectra, were presented already in previous reports. ${ }^{[1,67,103]}$ The schematic representation in Figure 1a displays the steps of the fabrication process of the biocomposites. The dispersion was homogenized using tip sonication. The ink was then deposited by spray-coating on both sides of the cotton substrate, which was simultaneously heated by a heat-gun at $120-140{ }^{\circ} \mathrm{C}$ to quickly evaporate the solvents. After spraying, the samples were oven treated at $190{ }^{\circ} \mathrm{C}$ for 1 hour to polymerize aleuritic acid in polyaleuritate (see chemical characterization in Figure S1). This treatment leaves the underlying cotton substrate intact, as shown in the thermogravimetric analysis of Figure S2. Flexible composite materials were obtained after this process. The micromorphology of the virgin cotton substrates appears as a fibrous mat with fibers of approximately 10-30 $\mu \mathrm{m}$ diameter (Figure 1b). On the other hand, biocomposites appear differently, depending on the carbon-nanofiller. In particular, the presence of an elongated nanomaterial (i.e., $\mathrm{CnFs}$ or $\mathrm{CnTs}$ ) results in structures with micro pores onto their surface, while GnPs-based samples exhibit nanoflakesrich surfaces, as displayed in Figures 1c and S3. The cross-sectional micromorphology of the cotton substrate and biocomposites is presented in Figures 1d-e and S4, indicating that polyaleuritate is gluing the cotton fibers together, preserving a compact structure after cut, as noticeable comparing the cross sections of bare cotton (Figure 1d) and of the composite material prepared with only aleuritic acid sprayed and cross linked on the cotton substrate (AC, Figure S4). The polymer is also partially absorbed by the cotton during polymerization, as observed in Figures S3 and S4, owing to melting during the oven treatment (melting point of aleuritic acid is $\sim 100-110^{\circ} \mathrm{C}$ ). The thickness of the different conductive coatings was estimated through SEM cross-section images of the carbon-based biocomposites and it was found to be $10 \pm 3 \mu \mathrm{m}, 19 \pm 5 \mu \mathrm{m}$, and $23 \pm 7 \mu \mathrm{m}$ for the coatings containing $40 \% \mathrm{CnFs}, 40 \%$ CnTs, and 40\% GnPs, respectively. The thickness of the deposition was controlled by keeping constant the surface of the cotton used as target $\left(5 \times 7 \mathrm{~cm}^{2}\right)$, the volume of sprayed ink $(4 \mathrm{ml})$ and the spray conditions (see materials section for more details). 


\section{WILEY-VCH}

a)
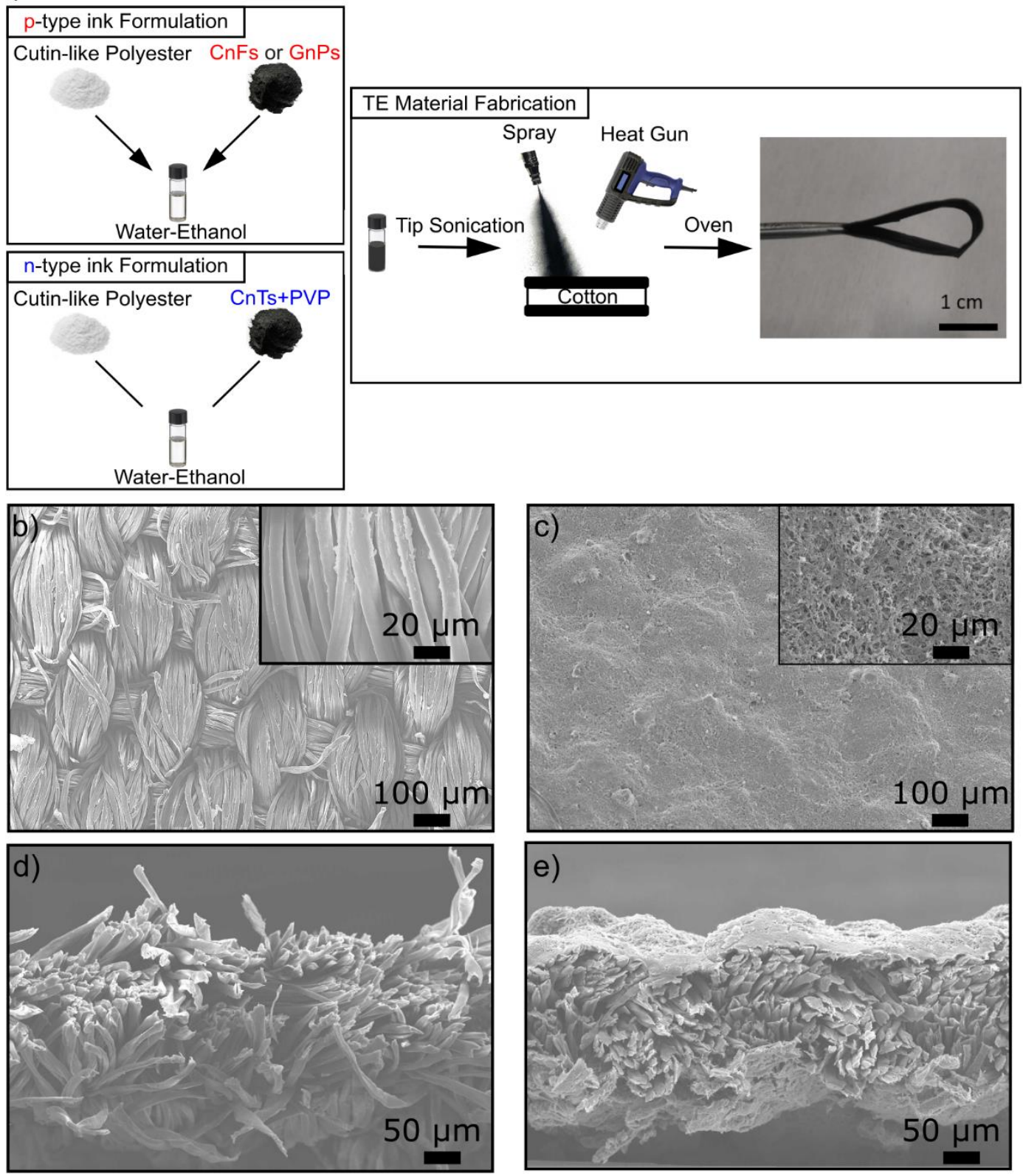

Figure 1. a) Schematic representation of the preparation of the samples and a picture of a biocomposite. b) and c) SEM images of the surface of the pure cotton substrate and $40 \%$ CnFs biocomposite sample, respectively. d) and e) SEM images of the cross sections of the pure cotton substrate and $40 \%$ CnFs biocomposite, respectively.

The biodegradability of the biocomposites was determined by BOD in seawater, mimicking the pelagic marine environment. ${ }^{[104]}$ Results are reported in Figure S5. Figure S5a shows the oxygen consumption by the microorganisms present in the seawater during the first 30 days $\left(\mathrm{BOD}_{30}\right)$. Oxygen consumption increases from pure cotton to polyaleuritate-containing samples. In particular, final BOD values range from $5 \mathrm{mg} / \mathrm{mL}$ for pure cotton to $11 \mathrm{mg} / \mathrm{mL}$ 


\section{WILEY-VCH}

for $40 \% \mathrm{CnTs}, 19 \mathrm{mg} / \mathrm{mL}$ for $40 \% \mathrm{GnPs}, 21 \mathrm{mg} / \mathrm{mL}$ for $40 \% \mathrm{CnFs}$, and $36 \mathrm{mg} / \mathrm{mL}$ for the AC samples. Important differences were found also between the times at which the samples start to degrade. In this sense, for the AC sample and the $40 \% \mathrm{CnFs}$, this time was 4 days, while for the rest of the samples it was 10 days. Figure S5b displays the weight losses after the BOD test. As for the oxygen consumption, the weight loss increases from pure cotton to $40 \% \mathrm{CnTs}$, 40\% GnPs, 40\% CnFs, and AC samples. Differences in maximum values of BOD, times before biodegradation, and final weight losses can be associated with the accessibility, crystallinity, nutritional value and concentration of the components of the biocomposites. ${ }^{[105]}$ In this sense, the secreted enzymes by the organisms present in the seawater can more easily access the amorphous polyaleuritate matrix than the high-crystalline cotton cellulose. ${ }^{[106-108]}$ As a general observation, the presence of carbon particles in the composites decreases the BOD compared to the cotton-polyaleuritate sample, most likely because of a lower concentration of polyaleuritate in the carbon particles-containing samples. In addition, the morphology of these samples can also affect their biodegradation. Thus, the porous and cavity-rich topography of the $\mathrm{AC}$ sample with $40 \% \mathrm{CnFs}$ can favor the interaction with the microorganisms responsible of the biodegradation, reducing the time before degradation. Finally, the morphology of the samples was studied after 30 days in seawater. As expected, for pure cotton fibers (Figure S5c), a similar morphology to the one before the BOD test was observed, indicating a low biodegradation of the sample in such conditions and times. For the samples containing 40\% CnTs and GnPs (Figures S5d and e), cotton fibers mainly appeared impregnated, whereas for the samples with $40 \%$ CNFs and AC (Figures S5f and g), most of the cotton fibers appear exposed.

The TE properties of the fabricated biocomposite materials were experimentally evaluated in a custom made setup. ${ }^{[109]}$ In particular, the Seebeck coefficient $(\alpha)$ and the sheet resistance $\left(R_{S}\right)$ of the samples were measured as a function of different amount of CnFs, GnPs, and CnTs 


\section{WILEY-VCH}

with respect to polyaleuritate, at room temperature. The values are reported in Table 1 and Table S1. The samples containing CnFs and GnPs show positive value of the Seebeck coefficient, indicating that they are $p$-type materials, i.e. the majority of the charge carriers are holes. On the contrary, the samples with CnTs possess negative value of Seebeck coefficient, typical of $n$-type materials, i.e. the majority of the charge carriers are electrons. In general, enhancing the percentage of conductive materials in the ink, i.e. CnFs, GnPs, and CnTs with respect to polyaleuritate, leads to a sensible decrease of $R_{S}$ in all the samples but does not significantly alter the Seebeck coefficient. Most likely, this is indicative of an increase of the thickness of the conductive coating layer, not affecting the materials electronic structure, and, in particular, the density of charge carriers of the systems at the Fermi level, which strongly affects the value of the Seebeck coefficient. ${ }^{[110,111]}$ Moreover, considering the thickness of the conductive coating layers of the samples made with $40 \% \mathrm{CnFs}, 40 \% \mathrm{GnPs}$, and $40 \% \mathrm{CnTs}$, their electrical conductivity $(\sigma$ ) can be calculated (see Table 1$)$. The samples with CnTs possess the largest electrical conductivity of $55 \pm 16 \mathrm{~S} \mathrm{~cm}^{-1}$. To further enhance the TE properties of the samples made with CnFs and GnPs, PEDOT:PSS, an organic $p$-type conductor, was added to the ink solution in a percentage of $20 \%$ relative to the weight of the dry aleuritic acid polymer. PEDOT:PSS has a Seebeck coefficient of $\sim 14 \mu \mathrm{V} / \mathrm{K}$ at room temperature (RT) and an electrical conductivity of $\sim 700 \mathrm{~S} / \mathrm{cm}$ at RT, both values larger with respect to the fabricated biocomposites. ${ }^{[12]}$ As reported in Table S1, the addition of PEDOT:PSS in CnFs biocomposites leads to a $25 \%$ enhancement of the Seebeck coefficient and a decrease of approximately one order of magnitude in $R_{\mathrm{S}}$. In the case of GnPs biocomposites, the addition of the polymer conductor enhances the Seebeck coefficient by $15 \%$ and reduces $R_{\mathrm{S}}$ by $50 \%$. In both cases, the $R_{\mathrm{S}}$ decrease is related to high conductivity of PEDOT:PSS. The enhancement in the Seebeck coefficient instead can suggest a slightly modification in the electronic structure of the resulting materials. It is worth noticing that the inclusion of PEDOT:PSS is not expected to substantially change the biological oxygen 


\section{WILEY-VCH}

demand of the biocomposites because this conductive polymer was added at a maximum load correspondent to the $5 \mathrm{wt} . \%$ of the total weight of the thermoelectric material.

Table 1. Reported measured values at room temperature of the TE properties of polyaleuritate-cotton composites with different percentages of CnFs, GnPs, and CnTs:PVP. In the first column the investigated materials are described (Samples), in the second one the abbreviation used in the text for each sample are shown (Label), and in the third and fourth the Seebeck coefficient $(\alpha)$ and sheet resistance $\left(R_{S}\right)$ are displayed, respectively. Final column $(\sigma)$ reports the electrical conductivity calculated using the thickness of the conductive coating.

\begin{tabular}{ccccc}
\hline Samples & Label & $\alpha\left[\mu \mathrm{V} \mathrm{K} \mathrm{K}^{-1}\right]$ & $\mathrm{R}_{\mathrm{S}}\left[\Omega \square^{-1}\right]$ & $\sigma\left[\mathrm{S} \mathrm{cm}^{-1}\right]$ \\
\hline AC cotton and 40\% CnFs & $40 \% \mathrm{CnFs}$ & $6.4 \pm 0.5$ & $(0.17 \pm 0.02)^{*} 10^{3}$ & $6.0 \pm 2.0$ \\
AC cotton and 40\% GnPs & $40 \%$ GnPs & $14 \pm 2$ & $(0.16 \pm 0.02)^{*} 10^{3}$ & $2.2 \pm 0.8$ \\
AC cotton and 40\% & $40 \%$ CnTs & $-3.2 \pm 0.8$ & $9.5 \pm 1.3$ & $55.0 \pm$ \\
CnTs:PVP (50:50) & & & & 16.0
\end{tabular}

Ideal compliant materials need to maintain their properties also after repeated bending.

Therefore, the bending stability of the electrical resistance of these biocomposites was tested after repeated cycles of curving and releasing the biocomposites and the results are reported in Figure 2. Only the samples presented in Table 1 were tested due to their balance between electrical conductivity and mechanical features (Figure S6). Indeed, they displayed stressstrain curves comparable to cellulose and cotton, as shown in Figure S6, and a remarkable sheet resistance (Table 1). Higher loadings resulted in fracturing of the conductive layer with bending, due to the brittleness induced by the high amount of carbon-based nanofillers. The tests were conducted changing the diameter of curvature of the biocomposites from 1.4 to 0.2 $\mathrm{cm}$ (top of Figure 2) and measuring the electrical resistance before and after each bending cycle. During the first three bending events at $1.4 \mathrm{~cm}$ curvature diameter, all samples showed a slight increase in resistance. In particular, the samples with the elongated nanofillers were more stable to bending compared to the sample with the nanoflakes. As the curvature diameter was reduced to $0.7 \mathrm{~cm}$ (bending events 4 to 6 ), the performance difference among the different samples broadened. Indeed, at the sixth bending cycle, the CnFs-based samples 


\section{WILEY-VCH}

roughly doubled the initial value of electrical resistance, while the CnTs value increased by nearly 4 times, and the GnPs-based samples showed an increase of one order of magnitude. The last three bending cycles at $0.2 \mathrm{~cm}$ curvature diameter (bending events 7 to 9) are even more pronounced in determining a change in the final value of resistance. In fact, after the bending event 9, the CnFs-based samples increased their electrical resistance by 5 times, the CnTs by 12 times, and the GnPs-based sample by nearly $10^{3}$ times. In addition, the CnFs- and GnPs-based samples with $20 \%$ of PEDOT:PSS were also investigated. Both the samples with PEDOT:PSS exhibited an enhanced stability to bending. In particular, the GnPs-based samples increased the electrical resistance by 13-14 times after the bending event 9 , while the CnFs-based biocomposites increased the resistance only by nearly 3 times. Hence, the geometry of the nanofiller is an important parameter to determine the bending stability of the final biocomposites. The higher is the aspect ratio of the filler, the better is the bending stability of the biocomposite. ${ }^{[51,113-115]}$ The elongated geometry helps in maintaining the percolative network and therefore efficient charge transport after bending-unbending cycles. Another positive effect on the bending stability is achieved when PEDOT:PSS is added to the formulation, further enhancing the robustness upon bending. Similar trends and conclusions are obtained measuring the stability of the electrical characteristics of the cotton-based nanocomposites before and after washing cycles, as reported in Figure S7. This procedure was performed for 1 hour at $40{ }^{\circ} \mathrm{C}$ and adding commercially available soap. The resistance of the material was measured before and after each washing treatment. The best results were obtained with the CNFs-based samples, which showed a increase in resistance of only $30 \%$ with respect to the initial value. GnP and $\mathrm{CnTs}$ samples underwent a larger modification, with an increase of four orders of magnitude and one order of magnitude, respectively. 


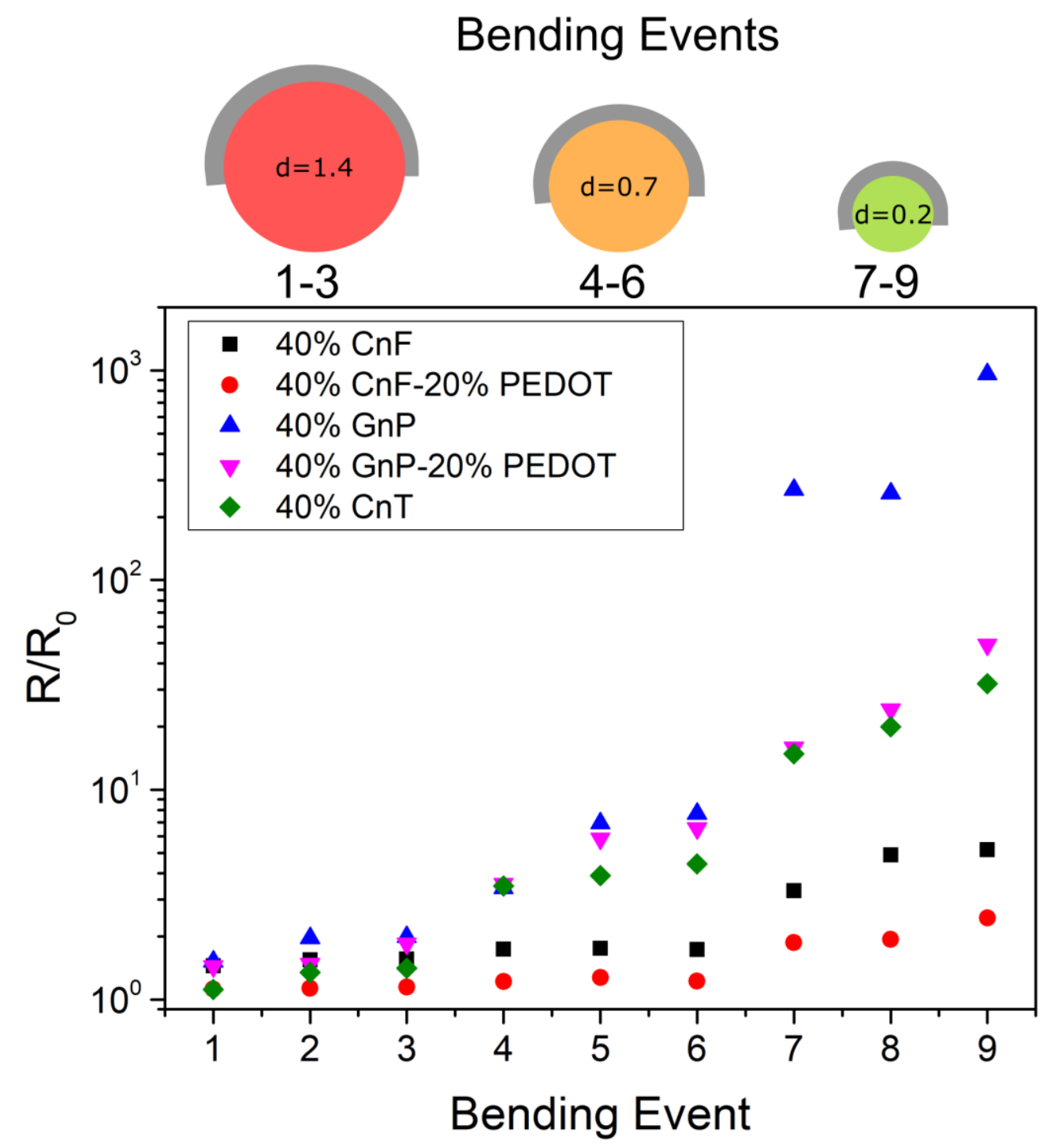

Figure 2. Bending stability of the plant-based biocomposites. At the top are schematized the bending cycles performed. $d$ indicates the diameter in $\mathrm{cm}$ at which the materials were bent. Three cycles were performed at each bending diameter. The lower graph reports the variation of the electrical resistance with bending cycles. $R$ represents the resistance after each bending cycle and $R_{0}$, the initial value of resistance.

Due to the promising TE features of the cotton-based materials, an in-plane prototype TEG was developed in order to explore the suitability of the biocomposites for e-textile applications. Figure 3a shows a schematic representation of a thermocouple, the building block of a TEG. The thermocouple consists of a $p$ - and $n$-type material connected electrically in series and thermally in parallel. The difference in temperature between the two sides of the thermocouple leads to the thermal diffusion of the charge carriers through both materials towards the cold junction. Thus, the temperature gradient $\Delta T=T_{\text {hot }}-T_{\text {cold }}$ creates an open 


\section{WILEY-VCH}

circuit voltage drop across the thermocouple $\left(\Delta V_{T C}\right)$ which is directly dependent on the difference of the Seebeck coefficients of the $p$-type $\left(\alpha_{1}\right)$ and of the $n$-type $\left(\alpha_{2}\right)$ materials through $\Delta V_{T C}=\left(\alpha_{1}-\alpha_{2}\right) \Delta T$. In general, TEG are composed of a large number $(N)$ of interconnected thermocouples, since the electrical potential generated by a single element is too low for any practical application. The output voltage drop across a TEG therefore is defined as:

$$
V_{\text {OUT }}=N\left(\alpha_{1}-\alpha_{2}\right) \Delta T
$$

To realize the thermocouple, we selected the $40 \% \mathrm{CnFs}$ material, showing good electrical stability after being bent and washed, for the $p$-type leg, and the $40 \%$ CnTs material for the $n$ type one. The thermocouple was fabricated with legs of both polarities around $9 \mathrm{~cm}$ long and $1 \mathrm{~cm}$ wide, inter-connected electrically in series using silver paint over a length of $1 \mathrm{~cm}$ at both ends and carbon conductive tape to connect external wires. Two proof-of-concept TEGs were realized and characterized, one consisting of a single thermocouple and one obtained by interconnecting two thermocouples (Figure 3b). The two ends of the TEGs were placed onto two hot plates, distant around $3 \mathrm{~cm}$, one kept at $R T$ (cold side) and the other controlled in a range from RT up to $130{ }^{\circ} \mathrm{C}$. The output voltage (VOUT) values of the TEGs as a function of $\Delta T\left(<110^{\circ} \mathrm{C}\right)$ are reported in Figure $3 \mathrm{c}$, and are in good agreement with the expected values given by Equation 1 (dotted lines in Figure 3c): $V_{O U T}$ increases linearly with $\Delta T$ and reaches a value of $0.7 \mathrm{mV}$ at $\Delta T \approx 70^{\circ} \mathrm{C}$ for the device with a single thermocouple $(N=1)$ and of 1.45 $\mathrm{mV}$ connecting 2 thermocouples $(N=2)$. Afterwards, the maximum output power $\left(P_{M A X}\right)$ of the device was calculated using the relation $P_{M A X}=V_{\text {OUT }} I$, thus measuring $V_{\text {OUT }}$ as a function of the load current $I$ (from 0 to $2 \mu \mathrm{A}$ ) at a fixed $\Delta T \approx 70^{\circ} \mathrm{C}$, as reported in Figure $3 \mathrm{~d}$. $P_{M A X} \approx$ $0.2 \mathrm{nW}$ for the device with $N=1$, while for $N=2, P_{M A X} \approx 0.3 \mathrm{nW}$. To check the accuracy of the experimental data, $P_{M A X}$ was also calculated according to the equation:

$$
P_{M A X}=\frac{V_{O U T}^{2}}{4 R_{I N}}
$$




\section{WILEY-VCH}

where $R_{I N}$ is the total internal resistance of the device, being $\sim 700$ and $\sim 1600 \Omega$ for $N=1$ and $N=2$, respectively. Calculated $P_{M A X}$ results $\sim 0.17 \mathrm{nW}$ for $N=1$, and $\sim 0.32 \mathrm{nW}$ for $N=2$, both in good agreement with the experimental values. To further enhance the $P_{M A X}$ of the devices, the TEG was then built substituting the $40 \% \mathrm{CnFs}$ material with $40 \% \mathrm{CnFs}+20 \%$ PEDOT:PSS, which has higher Seebeck coefficient and lower $R_{S}$. The measured VOUT as a function of $\Delta T$ is reported in Figure $3 \mathrm{e}$, reaching a value of $0.9 \mathrm{mV}$ at $\Delta T \approx 70^{\circ} \mathrm{C}$ for the device with $N=1$, and of $1.65 \mathrm{mV}$ for the device with $N=2$. As expected from Equation 1 (dotted lines in Figure 3e), both $V_{O U T}$ values are improved. Moreover, as shown in Figure 3f, $P_{M A X}$ at $\Delta T \approx 70^{\circ} \mathrm{C}$ as a function the load current $I$ (from 0 to $\sim 5 \mu \mathrm{A}$ ), reaches $\sim 0.55 \mathrm{nW}$ for $N=1$ and $\sim 1.0 \mathrm{nW}$ for $N=2$, again in good agreement with calculated data using Equation 2 $\left(0.44 \mathrm{nW}\right.$, with $R_{I N} \approx 350 \Omega$, and $\sim 0.9 \mathrm{nW}$, with $R_{I N} \approx 700 \Omega$, for $N=1$ and $N=2$, respectively).

Even though $\Delta T$ values in the range of $70^{\circ} \mathrm{C}$, or even higher, are often used in literature, from a practical point of view, such temperature difference is clearly not realistic for wearable applications.$^{[116]}$ To provide a more realistic example, we start by considering a1.7 $\mathrm{m}$ tall adult, of $70 \mathrm{~kg}$ of weight: the available body surface area is $\sim 1.47 \mathrm{~m}^{2}$, not counting the surface of the head, neck, feet and hands. ${ }^{[34]}$ Considering this surface fully covered by 1 TE element, the cross sectional area (i.e. perpendicular to the surface of the body) is $10^{-5} \mathrm{~cm}^{2}$. In this configuration, one side of the TE material will be in contact with the human skin and the other with the environment. Assuming a $\Delta \mathrm{T} \approx 20^{\circ} \mathrm{C}$, reasonable in winter, the calculated $P_{M A X}$ reaches values of $\sim 2 \mu \mathrm{W}$ and $\sim 6.6 \mu \mathrm{W}$ for a device with only nanofillers and with PEDOT:PSS addition, respectively. Therefore, although further development is required to achieve real-case applications, the potential of the reported materials can be already appreciated, since such power values could in principle meet the power needs of wearable electronic devices such as medical sensors, wristwatches and hearing aids. ${ }^{[34]}$ 


\section{WILEY-VCH}

To complete the TE characterization of the fabricated biocomposites, the in-plane thermal conductivity of the different samples was estimated by using an infrared-camera imaging method (Figure S8a-d). As expected, adding the conductive nanofillers to AC cotton enhances the total thermal conductivity of the systems, reaching values around $150 \mathrm{~W} \mathrm{~m}^{-1} \mathrm{~K}^{-1}$, two-three orders of magnitude higher than the thermal conductivity measured normally for organic semiconductor materials. ${ }^{[12]}$ Being the best TE materials electrically conductive and thermally insulating, such high measured thermal conductivity indicates a clear path for improvement of the conversion efficiency of biocomposites based TEGs, i.e. lowering thermal conductivity while maintaining green fabrication methodology and environmental friendly components. 


\section{WILEY-VCH}

a)

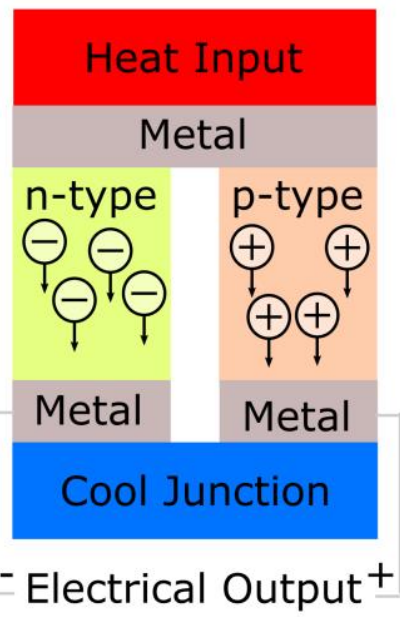

c)

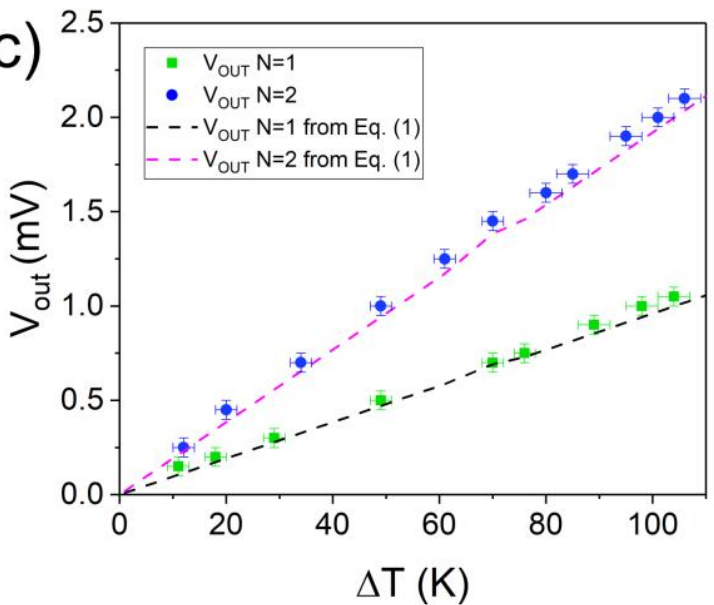

e)

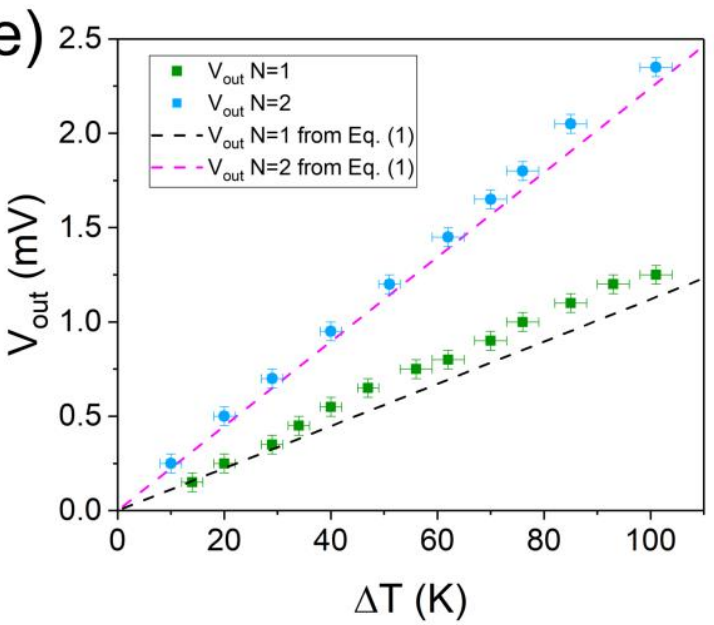

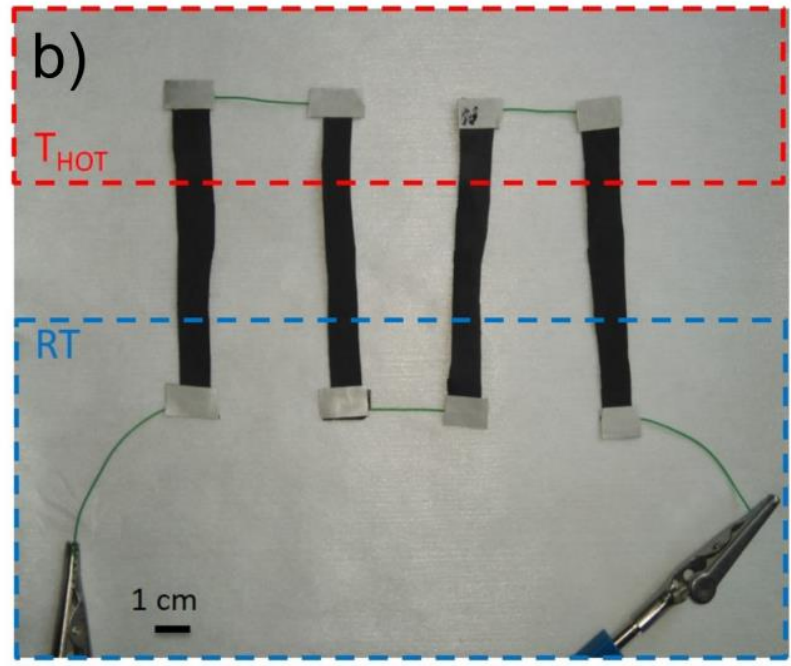

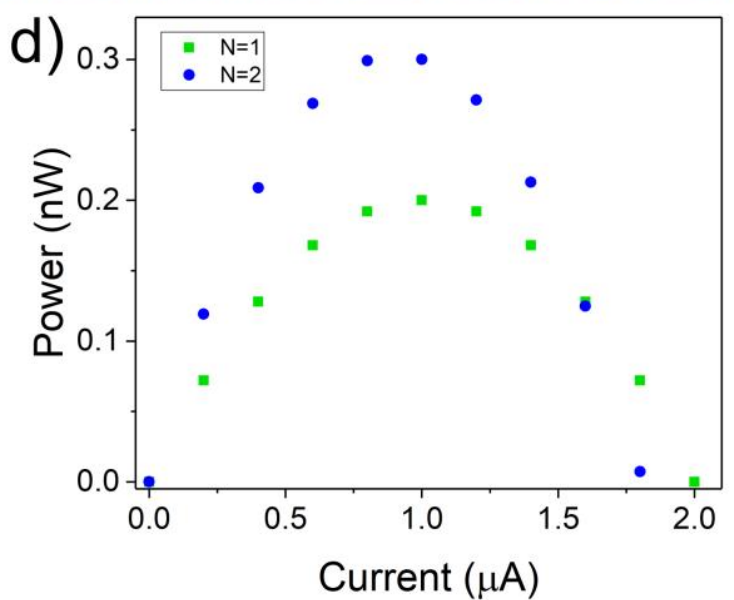

f)

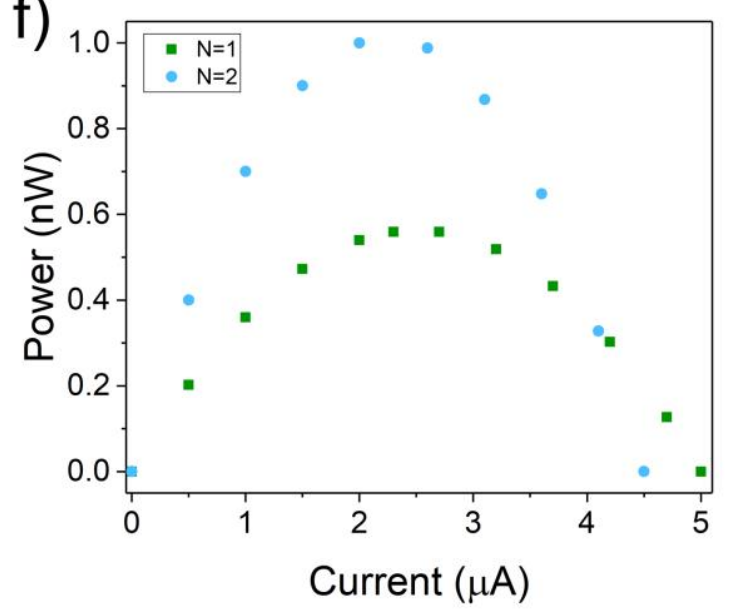

Figure 3. (a) Schematic of a simple TE module consisting of $1 p$ - and $n$-type materials $(N=$ 1); (b) Cotton-based in-plane TE device with $N=2$ TE elements composed by: $p$-type $40 \%$ CnFs, and $n$-type $40 \%$ CnTs (with red box $=$ hot plate and blue box $=$ room temperature plate) connected by silver paint and conducting wires fixed by conductive carbon tape on top; (c) Measurements of the output voltage ( $\left.V_{O U T}\right)$ as a function of the temperature gradient $(\Delta T)$ and calculated according to Equation 1 (dotted lines) for module composed by $N=1 \mathrm{TE}$ element (red circle) and $N=2 \mathrm{TE}$ elements (empty blue square); (d) Measurements of the output power $\left(P=V_{\text {OUT }} I\right)$ as a function of the measured current $I$ at $\Delta \mathrm{T} \sim 70^{\circ} \mathrm{C}$ for module composed by $N=1 \mathrm{TE}$ element (black square) and $N=2 \mathrm{TE}$ elements (empty red circle); (e) Measurements of $V_{O U T}$ as a function of $\Delta T$ and calculated according to Equation 1 (dotted line) for a module composed by $N=1 \mathrm{TE}$ element (black square) and $N=2$ TE elements 


\section{WILEY-VCH}

(empty red circle) of $p$-type $40 \% \mathrm{CnFs}+20 \%$ PEDOT:PSS, and $n$-type $40 \%$ CnTs; (f) Measurements of the output power as a function of the measured $I$ at $\Delta \mathrm{T} \sim 70^{\circ} \mathrm{C}$ for module composed by $N=1 \mathrm{TE}$ element (empty red circle) and $N=2 \mathrm{TE}$ elements (black square).

\section{Conclusions}

Flexible organic textile materials are proposed here as TE elements to generate electricity from heat gradients, being interesting power sources for wearable applications. The fabrication process was developed employing green and highly scalable methods, using polymers from bug resins (polyaleuritate) and carbon-based nanofillers. Biological oxygen demand tests confirmed the higher degradability of all the polyaleuritate-containing samples in comparison to pure and high crystalline cotton. The stability of the electrical properties to bending and washing cycles was found to be dependent on the kind of nanoparticle employed, with the CnFs-based samples showing the best performances, increasing the electrical resistance by 5 times after 9 cycles of bending at diameters ranging from 1.4 to $2 \mathrm{~mm}$, and by only $30 \%$ after being washed. Depending on the employed nanofiller, it was demonstrated the possibility to change the Seebeck coefficient of the biocomposites from positive, as in case of GnPs and CnFs, leading to $p$-type materials, to negative values, as for CnTs, obtaining an $n$ type material. Coupling the fabricated $p$ - and $n$-type TE materials, a flexible, textile-based, inplane, proof-of-concept TEG was realized, generating a maximum output power of $0.3 \mathrm{nW}$ at $\Delta T \approx 70^{\circ} \mathrm{C}$ when composed of two thermocouples. The addition of PEDOT:PSS to the $p$-type inks was found to slightly increase the Seebeck coefficient of the materials and to contemporarily decrease the sheet resistance of the samples, leading to an improved TE performance. As a result, the introduction of such modified $p$-type materials in TEGs fabricated with two thermocouples resulted in an increase of the maximum output power, reaching $\sim 1.0 \mathrm{nW}$ at $\Delta T \approx 70^{\circ} \mathrm{C}$. Due to the ease of fabrication, the green manufacturing and the flexibility and sustainability of the biocomposites, the presented TE materials lay the 


\section{WILEY-VCH}

foundation for a future generation of wearable TE devices, safer for the environments and more easily disposable.

\section{Experimental Section}

Materials

Cotton fabric was acquired from Cotonificio Albini (porosity of $\sim 10 \mu \mathrm{m}$, density of $\sim 120$

$\mathrm{g} / \mathrm{m}^{2}$ ). GnPs were donated by Directa Plus (grade Ultra G+, Raman spectrum, lateral size and thicknesses available in this previous report ${ }^{[67]}$ ). Graphitized CnFs (grade PR-25-XT-HHT from Pyrograf Products Inc.) with length between 20 and $200 \mu \mathrm{m}$ and diameter of $\sim 100 \mathrm{~nm}$ were purchased from Sigma-Aldrich. The $p$-type conductive inks was realized employing a concentration of $0.015 \mathrm{~g} \mathrm{~mL}^{-1}$ of aleuritic acid dispersed in equal volume of water and ethanol. First aleuritic acid was included into the ethanol and then after mixing for one minutes the water was added. As last step, different amounts of GnPs/CnFs nanoparticles, ranging from few percent to $80 \mathrm{wt} . \%$ with respect to the dry aleuritic acid were inserted into the ink formulation. The $n$-type conductive inks was prepared by employing a concentration of $0.015 \mathrm{~g} \mathrm{~mL}^{-1}$ of aleuritic acid dispersed in equal volume of water and ethanol. Another time, first aleuritic acid was included into ethanol and then after mixing for one minutes the water was added. Different amounts of CnTs nanoparticles (obtained by MWCnTs as reported by $^{[117,118]}$, ranging from $10 \%$ to $80 \mathrm{wt} . \%$ with respect to the dry polymer basis were added to the ink. The conductive ink with CnTs contained also an equal weight of PVP (approx. Mw 40000 Scientific Products). The samples with PEDOT:PSS (Clevios PJ700 purchased from Sigma Aldrich and used as received) were manufactured adding to the abovementioned formulations the indicated weight percent of conductive polymer, relative to the weight of the dry aleuritic acid biopolymer. The different inks were tip sonicated $(750 \mathrm{~W}, 40 \%$ amplitude, $20 \mathrm{kHz}, 4$ times for $30 \mathrm{~s}$ ) using a Sonics \& Materials, Inc. (Model Num. VCX750), to achieve an homogeneous dispersion. Suddenly after, the inks were sprayed (distance of $18-20 \mathrm{~cm}$, 
pressure of 2.0 bar) on cotton rectangles ( $4 \mathrm{~mL}$ on each side, $3 \times 5 \mathrm{~cm}^{2}$ ) and simultaneously heat gun at $120-140^{\circ} \mathrm{C}$. The aleuritic acid was then heat-cured in the oven at $190^{\circ} \mathrm{C}$ and polymerized in polyaluritate. ${ }^{[102]}$

As an example, we report the exact formulation of the $40 \mathrm{wt} . \% \mathrm{GnPs}$ loaded sample with also 20 wt.\% of PEDOT. $0.45 \mathrm{~g}$ of aleuritic acid were dispersed inside $15 \mathrm{~mL}$ of ethanol. After one minute of mixing, $15 \mathrm{ml}$ of water were added. Then $0.18 \mathrm{~g}$ of GnPs inserted into the ink. Last, $0.09 \mathrm{~g}$ of PEDOT were added to the ink formulation. After tip sonication, the ink was ready for praying.

It is noteworthy that high amount of nanofillers (i.e. $80 \mathrm{wt}$ \%) strongly enhance the viscosity of the inks, increasing the difficulty to obtain a homogeneous coating and facilitating the clogging of the spray nozzle.

Methods

At least four samples were tested for each measurement unless specified differently. Scanning Electron Microscopy

SEM pictures were obtained using a microscope from JEOL (model JSM-6490LA). The images were acquired setting an acceleration voltage of $15 \mathrm{kV}$ and recording the secondary electron emission. The distance between the samples and the SEM aperture was $1 \mathrm{~cm}$. The samples for cross section imaging were cut at $-195.79^{\circ} \mathrm{C}$ in liquid nitrogen by tearing them with two tweezers to preserve the original morphology.

Biochemical Oxygen Demand (BOD)

Biodegradability was evaluated through a standard biochemical oxygen demand (BOD) test by measuring of the oxygen amount consumed during a month in a biodegradation reaction in water. For each sample, three measurements were collected and the results were averaged to obtain a mean value. Carefully weighed samples $(\sim 200 \mathrm{mg})$ were finely minced and immersed in $432 \mathrm{~mL}$ bottles containing seawater collected from the Genoa (Italy) area shoreline.

Oxygen consumed during the biodegradation process was recorded at different time intervals 


\section{WILEY-VCH}

by using sealed OxyTop caps on each bottle which can assess the oxygen levels. BOD from blank bottles filled with only seawater was also measured for reference.

Mechanical Characterization

A uniaxial testing apparatus (Instron 3365) was exploited to measure the mechanical characteristics of the biocomposites and of the pure cotton (strain rate $5 \mathrm{~mm} / \mathrm{min}$, starting length $25 \mathrm{~mm}$ and width $4 \mathrm{~mm}$ ). The thicknesses of the different samples was measured using a micrometer (Mitutoyo; series 293).

Thermal Characterization

The in-plane thermal conductivity was measured following the method of this paper ${ }^{[62]}$. Thermoelectric Characterization

For the measurements of the Seebeck coefficient and sheet resistance at room temperature we employed the homemade setup described by Beretta et al.. ${ }^{[59]}$ The measurements were done under vacuum condition of $10^{-4}$ mbar to avoid convection phenomena and on piece of samples $2 \times 1 \mathrm{~cm}^{2}$.

\section{Electrical Characterization}

The output voltages of the devices as a function of different temperature gradients were measured through an Agilent Storage Oscilloscope (DSO9064A) and the maximum output power for a variety of load current through an Agilent Precision Source/Measure Unit (B2912A). The temperature of the two sides of the device was measured with an Infrared Thermometer RS Pro 1327.

Description of the bending and washing cycles

The samples were bent around cylinders of different diameters $(d)$, as reported schematically in Figure 2, and keep onto the object for 5 minutes, making one bending event. The washing cycle was performed using a commercial beaker with distilled water and commercial soap put onto a laboratory hot plate. The samples were put in water and soap and washed for 1 hour 


\section{WILEY-VCH}

under stirring at $40{ }^{\circ} \mathrm{C}$ using a magnetic steer. Before and after each bending or washing cycle, the resistance of the samples was detected with a Multimeter Agilent U1241B. Fourier Transformed Infrared Spectroscopy Infrared spectra of the samples were acquired through an attenuated total reflectance (ATR) device (MIRacle ATR, PIKE Technologies) coupled to FTIR spectrometer (FT/IR - 4100, JASCO). All measurements were recorded with a resolution of $4 \mathrm{~cm}^{-1}$ resolution, in the range from 3800 to $600 \mathrm{~cm}^{-1}$ and collecting 128 scans. During measurements, the biocomposites were placed on the spot of the ATR device and gently pressed.

Thermogravimetric Analysis

TGA of the samples was finalized using a TA instruments machine (model Q500) in $\mathrm{N}_{2}$ conditioned environment. The samples were heated from 40 to 800 Celsius.

Supporting Information

Supporting Information is available free of charge from the Wiley Online Library.

Acknowledgments

We acknowledge Lara Marini for the TGA measurements. We acknowledge also DIRECTA PLUS S.p.A. for providing the graphene nanoplatelets.

\section{References}

[1] S. J. Kim, J. H. We, B. J. Cho, Energy \& Environmental Science 2014, 7, 1959.

[2] M. Stoppa, A. Chiolerio, Sensors (Basel) 2014, 14, 11957.

[3] K. Mamtani, https://www.alliedmarketresearch.com/wearable-technology-market, 2017.

[4] S. Takamatsu, T. Lonjaret, D. Crisp, J.-M. Badier, G. G. Malliaras, E. Ismailova, Scientific reports 2015, 5, 15003.

[5] Y. Du, K. Cai, S. Chen, H. Wang, S. Z. Shen, R. Donelson, T. Lin, Sci Rep 2015, 5, 6411. 


\section{WILEY-VCH}

[6] J. A. Lee, A. E. Aliev, J. S. Bykova, M. J. de Andrade, D. Kim, H. J. Sim, X. Lepro, A. A. Zakhidov, J. B. Lee, G. M. Spinks, S. Roth, S. J. Kim, R. H. Baughman, Adv Mater 2016, 28, 5038.

[7] J. D. Ryan, D. A. Mengistie, R. Gabrielsson, A. Lund, C. Muller, ACS Appl Mater Interfaces 2017, 9, 9045 .

[8] D. M. Rowe, Thermoelectrics handbook: macro to nano, CRC press, 2018.

[9] L. E. Bell, Science 2008, 321, 1457.

[10] M. Cassinelli, S. Müller, K.-O. Voss, C. Trautmann, F. Völklein, J. Gooth, K. Nielsch, M. Toimil-Molares, Nanoscale 2017, 9, 3169.

[11] M. Cassinelli, S. Müller, Z. Aabdin, N. Peranio, O. Eibl, C. Trautmann, M. ToimilMolares, Nuclear Instruments and Methods in Physics Research Section B: Beam Interactions with Materials and Atoms 2015, 365, 668.

[12] G. J. Snyder, E. S. Toberer, Nat Mater 2008, 7, 105.

[13] J.-H. Bahk, H. Fang, K. Yazawa, A. Shakouri, Journal of Materials Chemistry C 2015, 3, 10362.

[14] D. Zhao, G. Tan, Applied Thermal Engineering 2014, 66, 15.

[15] K. Davami, J.-S. Lee, M. Meyyappan, Transactions on electrical and electronic materials 2011, 12, 227.

[16] S. F. Tie, C. W. Tan, Renew Sust Energ Rev 2013, 20, 82.

[17] T. M. Tritt, Annual Review of Materials Research, Vol 41 2011, 41, 433.

[18] S. Y. Wang, Y. X. Sun, J. Yang, B. Duan, L. H. Wu, W. Q. Zhang, J. H. Yang, Energy \& Environmental Science 2016, 9, 3436.

[19] J. A. Wiklund, J. L. Kirk, D. C. G. Muir, J. Carrier, A. Gleason, F. Yang, M. Evans, J. Keating, Environ Sci Technol 2018, 52, 6137.

[20] S. L. Kim, K. Choi, A. Tazebay, C. Yu, ACS Nano 2014, 8, 2377.

[21] J. D. Ryan, A. Lund, A. I. Hofmann, R. Kroon, R. Sarabia-Riquelme, M. C.

Weisenberger, C. Muller, ACS Appl Energy Mater 2018, 1, 2934.

[22] G. B. Haxel, J. B. Hedrick, G. J. Orris, P. H. Stauffer, J. W. Hendley II, 2002.

[23] D. R. Lide, CRC handbook of chemistry and physics, Vol. 85, CRC press, 2004.

[24] C. A. Hewitt, A. B. Kaiser, S. Roth, M. Craps, R. Czerw, D. L. Carroll, Nano Lett 2012, 12, 1307.

[25] S. LeBlanc, Sustainable Materials and Technologies 2014, 1, 26.

[26] D. Beretta, N. Neophytou, J. M. Hodges, M. G. Kanatzidis, D. Narducci, M. MartinGonzalez, M. Beekman, B. Balke, G. Cerretti, W. Tremel, Materials Science and Engineering: R: Reports 2018.

[27] G. Tan, L.-D. Zhao, M. G. Kanatzidis, Chemical reviews 2016, 116, 12123.

[28] A. Nozariasbmarz, A. Agarwal, Z. A. Coutant, M. J. Hall, J. Liu, R. Liu, A. Malhotra, P. Norouzzadeh, M. C. Oeztuerk, V. P. Ramesh, Japanese Journal of Applied Physics 2017, 56, 05 DA04.

[29] X. Lu, D. T. Morelli, Y. Xia, F. Zhou, V. Ozolins, H. Chi, X. Zhou, C. Uher, Advanced Energy Materials 2013, 3, 342.

[30] M. Zhou, G. J. Snyder, L. Li, L.-D. Zhao, Inorganic Chemistry Frontiers 2016, 3, 1449.

[31] A. J. Karttunen, L. Sarnes, R. Townsend, J. Mikkonen, M. Karppinen, Advanced Electronic Materials 2017, 3, 1600459.

[32] M. Cassinelli, A. Romanenko, H. Reith, F. Volklein, W. Sigle, C. Trautmann, M. E. Toimil-Molares, Physica Status Solidi a-Applications and Materials Science 2016, 213, 603. [33] W. G. Ma, Y. J. Liu, S. Yan, T. T. Miao, S. Y. Shi, Z. Xu, X. Zhang, C. Gao, Nano Research 2018, 11, 741.

[34] P. Li, Y. Guo, J. K. Mu, H. Z. Wang, Q. H. Zhang, Y. G. Li, Rsc Adv 2016, 6, 90347. 


\section{WILEY-VCH}

[35] R. Kroon, D. A. Mengistie, D. Kiefer, J. Hynynen, J. D. Ryan, L. Yu, C. Müller, Chemical Society Reviews 2016, 45, 6147.

[36] M. Ito, T. Koizumi, H. Kojima, T. Saito, M. Nakamura, Journal of Materials Chemistry A 2017, 5, 12068.

[37] C. Cho, K. L. Wallace, P. Tzeng, J. H. Hsu, C. Yu, J. C. Grunlan, Advanced Energy Materials 2016, 6, 1502168.

[38] K. Kirihara, Q. Wei, M. Mukaida, T. Ishida, Synthetic Metals 2017, 225, 41.

[39] P. Cataldi, L. Ceseracciu, A. Athanassiou, I. S. Bayer, ACS applied materials \& interfaces 2017, 9, 13825.

[40] H. Yang, H. Zhu, M. M. Hendrix, N. J. Lousberg, G. de With, A. C. Esteves, J. H. Xin, Adv Mater 2013, 25, 1150.

[41] M. Shateri-Khalilabad, M. E. Yazdanshenas, Carbohydr Polym 2013, 96, 190.

[42] M. Stoppa, A. Chiolerio, Sensors 2014, 14, 11957.

[43] P. Cataldi, A. Athanassiou, I. S. Bayer, Appl Sci-Basel 2018, 8, 1438.

[44] M. Culebras, K. Choi, C. Cho, Micromachines (Basel) 2018, 9, 638.

[45] K. Zhang, J. Qiu, S. Wang, Nanoscale 2016, 8, 8033.

[46] G. J. Snyder, E. S. Toberer, in Materials For Sustainable Energy: A Collection of Peer-Reviewed Research and Review Articles from Nature Publishing Group, World Scientific, 2011, 101.

[47] X. Zhang, L. D. Zhao, Journal of Materiomics 2015, 1, 92.

[48] C. H. Yu, A. Murali, K. W. Choi, Y. Ryu, Energy \& Environmental Science 2012, 5, 9481.

[49] B. Poudel, Q. Hao, Y. Ma, Y. Lan, A. Minnich, B. Yu, X. Yan, D. Wang, A. Muto, D. Vashaee, X. Chen, J. Liu, M. S. Dresselhaus, G. Chen, Z. Ren, Science 2008, 320, 634.

[50] P. Cataldi, I. S. Bayer, F. Bonaccorso, V. Pellegrini, A. Athanassiou, R. Cingolani, Advanced Electronic Materials 2015, 1, 1500224.

[51] P. Cataldi, S. Dussoni, L. Ceseracciu, M. Maggiali, L. Natale, G. Metta, A. Athanassiou, I. S. Bayer, Adv Sci (Weinh) 2018, 5, 1700587.

[52] P. Cataldi, L. Ceseracciu, S. Marras, A. Athanassiou, I. S. Bayer, Applied Physics Letters 2017, 110, 121904.

[53] P. Cataldi, J. A. Heredia - Guerrero, S. Guzman - Puyol, L. Ceseracciu, L. La Notte, A. Reale, J. Ren, Y. Zhang, L. Liu, M. Miscuglio, Advanced Sustainable Systems 2018, 2, 1800069.

[54] P. Cataldi, O. Condurache, D. Spirito, R. Krahne, I. S. Bayer, A. Athanassiou, G. Perotto, ACS Sustainable Chemistry \& Engineering 2019.

[55] C. Bounioux, P. Díaz-Chao, M. Campoy-Quiles, M. S. Martín-González, A. R. Goni, R. Yerushalmi-Rozen, C. Müller, Energy \& Environmental Science 2013, 6, 918.

[56] M. Jouni, D. Djurado, V. Massardier, G. Boiteux, Polymer International 2017, 66, 1237.

[57] M. Nakano, T. Nakashima, T. Kawai, Y. Nonoguchi, Small 2017, 13, 1700804.

[58] B. Dörling, J. D. Ryan, J. D. Craddock, A. Sorrentino, A. E. Basaty, A. Gomez, M.

Garriga, E. Pereiro, J. E. Anthony, M. C. Weisenberger, Advanced Materials 2016, 28, 2782.

[59] C. Cho, M. Culebras, K. L. Wallace, Y. Song, K. Holder, J.-H. Hsu, C. Yu, J. C. Grunlan, Nano Energy 2016, 28, 426.

[60] C.-K. Mai, B. Russ, S. L. Fronk, N. Hu, M. B. Chan-Park, J. J. Urban, R. A.

Segalman, M. L. Chabinyc, G. C. Bazan, Energy \& Environmental Science 2015, 8, 2341.

[61] Y. J. Zheng, Y. L. Li, K. Dai, Y. Wang, G. Q. Zheng, C. T. Liu, C. Y. Shen,

Composites Science and Technology 2018, 156, 276.

[62] M. Zahid, M. T. Masood, A. Athanassiou, I. S. Bayer, Applied Physics Letters 2018, $113,044103$. 


\section{WILEY-VCH}

[63] S. Y. Yang, W. N. Lin, Y. L. Huang, H. W. Tien, J. Y. Wang, C. C. M. Ma, S. M. Li, Y. S. Wang, Carbon 2011, 49, 793.

[64] P. Cataldi, F. Bonaccorso, A. Esau del Rio Castillo, V. Pellegrini, Z. Jiang, L. Liu, N. Boccardo, M. Canepa, R. Cingolani, A. Athanassiou, Advanced Electronic Materials 2016, 2, 1600245.

[65] D. H. Wicaksono, B. Benhanan, D. E. Parung, F. Ughi, A. Shafi, S. Mandala, V. Biben, N. Maulana, F. Arisanti, Y. Herbani, "Carbon Nanotube-Coated Thread as Sensor for Wearable Mechanomyography of Leg Muscles", presented at 2018 IEEE SENSORS, 2018.

[66] I. A. Kinloch, J. Suhr, J. Lou, R. J. Young, P. M. Ajayan, Science 2018, 362, 547.

[67] P. Cataldi, I. S. Bayer, G. Nanni, A. Athanassiou, F. Bonaccorso, V. Pellegrini, A. E. D. Castillo, F. Ricciardella, S. Artyukhin, M. A. Tronche, Y. Gogotsi, R. Cingolani, Carbon 2016, 109, 331.

[68] Y. B. Cui, S. I. Kundalwal, S. Kumar, Carbon 2016, 98, 313.

[69] L. La Notte, P. Cataldi, L. Ceseracciu, I. S. Bayer, A. Athanassiou, S. Marras, E. Villari, F. Brunetti, A. Reale, Materials Today Energy 2018, 7, 105.

[70] P. Cataldi, J. A. Heredia - Guerrero, S. Guzman - Puyol, L. Ceseracciu, L. La Notte, A. Reale, J. Ren, Y. Zhang, L. Liu, M. Miscuglio, P. Savi, S. Piazza, M. Duocastella, G. Perotto, A. Athanassiou, I. S. Bayer, Advanced Sustainable Systems 2018, 1800069.

[71] S. N. Habisreutinger, T. Leijtens, G. E. Eperon, S. D. Stranks, R. J. Nicholas, H. J. Snaith, Nano Lett 2014, 14, 5561.

[72] M. H. Al-Saleh, W. H. Saadeh, U. Sundararaj, Carbon 2013, 60, 146.

[73] L. Chen, M. Weng, W. Zhang, Z. Zhou, Y. Zhou, D. Xia, J. Li, Z. Huang, C. Liu, S. Fan, Nanoscale 2016, 8, 6877.

[74] M. X. Piao, G. Kim, G. P. Kennedy, S. Roth, U. Dettlaff-Weglikowska, Physica Status Solidi B-Basic Solid State Physics 2013, 250, 2529.

[75] E. S. Kim, J. Y. Hwang, K. H. Lee, H. Ohta, Y. H. Lee, S. W. Kim, Adv Mater 2017, 29, 1604899.

[76] S. N. Patel, A. M. Glaudell, K. A. Peterson, E. M. Thomas, K. A. O’Hara, E. Lim, M. L. Chabinyc, Science advances 2017, 3, e1700434.

[77] G. Zuo, X. Liu, M. Fahlman, M. Kemerink, Advanced Functional Materials 2018, 28, 1703280.

[78] Q. Wu, J. L. Hu, Composites Part B-Engineering 2016, 107, 59.

[79] Q. Wu, J. L. Hu, Smart Materials and Structures 2017, 26, 045037.

[80] D. Kiefer, L. Yu, E. Fransson, A. Gómez, D. Primetzhofer, A. Amassian, M.

Campoy - Quiles, C. Müller, Advanced Science 2017, 4, 1600203.

[81] D. Kiefer, A. Giovannitti, H. Sun, T. Biskup, A. Hofmann, M. Koopmans, C. Cendra, S. Weber, L. J. Anton Koster, E. Olsson, ACS energy letters 2018, 3, 278.

[82] B. Russ, A. Glaudell, J. J. Urban, M. L. Chabinyc, R. A. Segalman, Nature Reviews Materials 2016, 1, 16050.

[83] D. X. Crispin, Energy \& Environmental Science 2012.

[84] O. Bubnova, Z. U. Khan, H. Wang, S. Braun, D. R. Evans, M. Fabretto, P. Hojati-

Talemi, D. Dagnelund, J.-B. Arlin, Y. H. Geerts, Nature materials 2014, 13, 190.

[85] R. Kroon, D. Kiefer, D. Stegerer, L. Yu, M. Sommer, C. Müller, Advanced Materials 2017, 29, 1700930.

[86] J. Liu, M. P. Garman, J. Dong, B. v. d. Zee, L. Qiu, G. Portale, J. C. Hummelen, L. J. A. Koster, ACS Applied Energy Materials 2019.

[87] G. Zuo, Z. Li, E. Wang, M. Kemerink, Advanced Electronic Materials 2018, 4, 1700501.

[88] K. Kang, S. Schott, D. Venkateshvaran, K. Broch, G. Schweicher, D. Harkin, C. Jellett, C. Nielsen, I. McCulloch, H. Sirringhaus, Materials Today Physics 2019, 8, 112. 


\section{WILEY-VCH}

[89] D. Venkateshvaran, K. Broch, C. N. Warwick, H. Sirringhaus, "Thermoelectric transport properties of high mobility organic semiconductors", presented at Organic FieldEffect Transistors XV, 2016.

[90] Y. Lu, Z.-D. Yu, R.-Z. Zhang, Z.-F. Yao, H.-Y. You, L. Jiang, H.-I. Un, B.-W. Dong, M. Xiong, J.-Y. Wang, Angewandte Chemie International Edition 2019.

[91] S. Wang, H. Sun, T. Erdmann, G. Wang, D. Fazzi, U. Lappan, Y. Puttisong, Z. Chen, M. Berggren, X. Crispin, Advanced Materials 2018, 30, 1801898.

[92] Z. Li, H. Sun, C. L. Hsiao, Y. Yao, Y. Xiao, M. Shahi, Y. Jin, A. Cruce, X. Liu, Y. Jiang, Advanced Electronic Materials 2018, 4, 1700496.

[93] J. Pei, X. B. Lu, B. Yu, Z. X. Yu, Asian Journal of Organic Chemistry 2018, 7, 489.

[94] A. Heredia, Biochim Biophys Acta 2003, 1620, 1.

[95] J. J. Benitez, J. A. Heredia-Guerrero, M. I. de Vargas-Parody, M. A. Cruz-Carrillo, V. Morales-Florez, N. de la Rosa-Fox, A. Heredia, Journal of Physics D-Applied Physics 2016, 49, 175601.

[96] J. A. Heredia-Guerrero, A. Heredia, E. Dominguez, R. Cingolani, I. S. Bayer, A. Athanassiou, J. J. Benitez, Journal of Experimental Botany 2017, 68, 5401.

[97] J. J. Benitez, J. A. Heredia-Guerrero, S. Guzman-Puyol, M. J. Barthel, E. Dominguez, A. Heredia, Frontiers in Materials 2015, 2, 59.

[98] J. J. Benítez, J. A. Heredia - Guerrero, S. Guzmán - Puyol, E. Domínguez, A.

Heredia, Journal of Applied Polymer Science 2015, 132.

[99] J. A. Heredia-Guerrero, A. Heredia, R. Garcia-Segura, J. J. Benitez, Polymer 2009, 50, 5633.

[100] J. A. Heredia-Guerrero, L. Goldoni, J. J. Benitez, A. Davis, L. Ceseracciu, R. Cingolani, I. S. Bayer, T. Heinze, A. Koschella, A. Heredia, A. Athanassiou, Carbohydr Polym 2017, 173, 312.

[101] K. Li, W. W. Zhang, X. J. Shi, L. X. Liu, K. Li, J. Xu, J. J. Ma, H. Zhang, Materials Research Express 2019, 6, 075328.

[102] J. A. Heredia - Guerrero, J. J. Benítez, P. Cataldi, U. C. Paul, M. Contardi, R.

Cingolani, I. S. Bayer, A. Heredia, A. Athanassiou, Advanced Sustainable Systems 2017, 1, 1600024.

[103] R. Sarabia-Riquelme, J. Craddock, E. A. Morris, D. Eaton, R. Andrews, J. Anthony, M. C. Weisenberger, Synthetic Metals 2017, 225, 86.

[104] L. Ceseracciu, J. A. Heredia-Guerrero, S. Dante, A. Athanassiou, I. S. Bayer, ACS Appl Mater Interfaces 2015, 7, 3742.

[105] L. Segal, M. L. Nelson, C. M. Conrad, J Phys Colloid Chem 1951, 55, 325.

[106] M. Ioelovich, E. Morag, BioResources 2011, 6, 2818_2835.

[107] H. Zhao, J. H. Kwak, Z. C. Zhang, H. M. Brown, B. W. Arey, J. E. Holladay, Carbohydrate polymers 2007, 68, 235.

[108] J. J. Benítez, J. A. Heredia-Guerrero, S. Guzmán-Puyol, E. Domínguez, A. Heredia, Soft Materials 2015, 13, 5.

[109] D. Beretta, P. Bruno, G. Lanzani, M. Caironi, Review of Scientific Instruments 2015, $86,075104$.

[110] L. D. Hicks, M. S. Dresselhaus, Phys Rev B Condens Matter 1993, 47, 12727.

[111] L. D. Hicks, M. S. Dresselhaus, Phys Rev B Condens Matter 1993, 47, 16631.

[112] D. Beretta, A. J. Barker, I. Maqueira-Albo, A. Calloni, G. Bussetti, G. Dell'Erba, A.

Luzio, L. Duo, A. Petrozza, G. Lanzani, M. Caironi, ACS Appl Mater Interfaces 2017, 9, 18151.

[113] A. V. Alaferdov, R. Savu, T. Rackauskas, S. Rackauskas, M. Canesqui, D. De Lara, G. Setti, E. Joanni, G. De Trindade, U. Lima, Nanotechnology 2016, 27, 375501.

[114] S. Tadakaluru, W. Thongsuwan, P. Singjai, Sensors 2014, 14, 868. 


\section{WILEY-VCH}

[115] C. Yan, J. Wang, W. Kang, M. Cui, X. Wang, C. Y. Foo, K. J. Chee, P. S. Lee, Advanced materials 2014, 26, 2022.

[116] Y. Du, J. Xu, B. Paul, P. Eklund, Applied Materials Today 2018, 12, 366.

[117] R. Andrews, D. Jacques, A. M. Rao, F. Derbyshire, D. Qian, X. Fan, E. C. Dickey, J.

Chen, Chemical Physics Letters 1999, 303, 467.

[118] D. N. Jacques, R. J. Andrews, Google Patents, 2007.

[119] A.-J. N. Khalifa, Energy conversion and management 2001, 42, 491. 


\section{WILEY-VCH}

Table of content

Current thermoelectric (TE) generators are rigid, not-environmentally friendly devices, thus unsuitable for wearable applications. Here, flexible TE materials are obtained spraying cotton with green inks constituted of cutin-like biopolyester, and carbon-based conductive nanofillers, such as graphene or carbon nanotubes. A switch from $p$ - to $n$-type TE materials is achieved depending on the nanofiller employed. In-plane wearable TE generator are demonstrated.
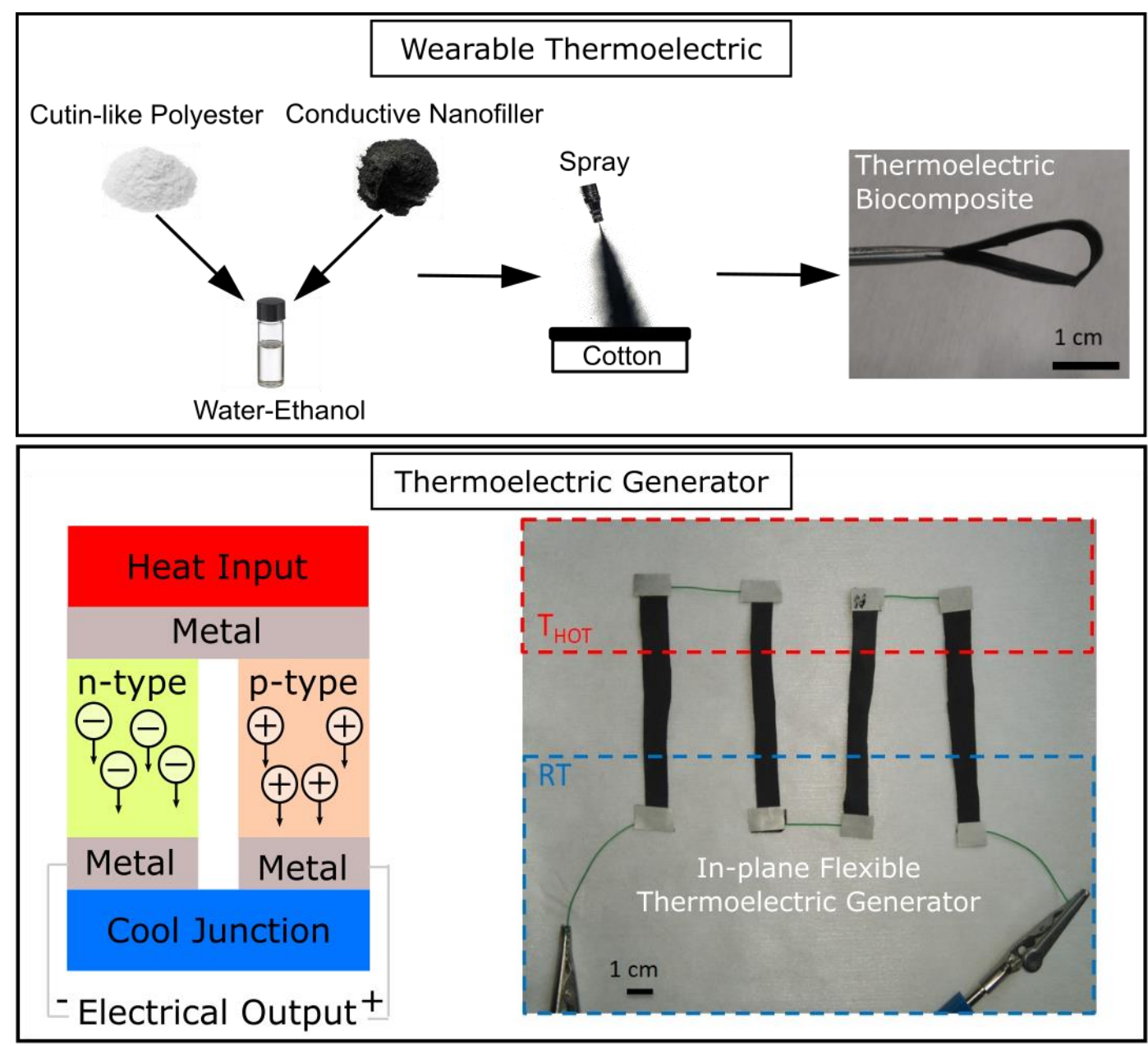


\section{WILEY-VCH}

Copyright WILEY-VCH Verlag GmbH \& Co. KGaA, 69469 Weinheim, Germany, 2016.

\section{Supporting Information}

\section{Green Biocomposites for Thermoelectric Wearable Applications}

Pietro Cataldi ${ }^{\dagger^{*}}$ and Marco Cassinelli, José A. Heredia-Guerrero, Susana Guzman-Puyol, Sara Naderizadeh, Athanassia Athanassiou, and Mario Caironi ${ }^{*}$ (P. Cataldi and M. Cassinelli contributed equally and are both first authors)

Dr. P. Cataldi, Dr. J.A. Heredia-Guerrero, Dr. S. Guzman-Puyol, S. Naderizadeh, Dr. A. Athanassiou

Smart Materials, Istituto Italiano di Tecnologia

Via Morego 30, 16163 Genova, Italy.

Email: pietro.cataldi@manchester.ac.uk

Dr. M. Cassinelli, Dr. M. Caironi

Center for Nano Science and Technology @PoliMi, Istituto Italiano di Tecnologia

Via Pascoli 70/3, Milano 20133, Italy.

Email: mario.caironi@iit.it

Present Addresses

$\dagger$ National Graphene Institute, University of Manchester, Booth Street East, Manchester M13 9PL, United Kingdom

Keywords: organic thermoelectrics, carbon nanotubes, graphene nanoplatelets, $n$-type thermoelectric materials, sustainable thermoelectric, carbon nanofibers 


\section{WILEY-VCH}

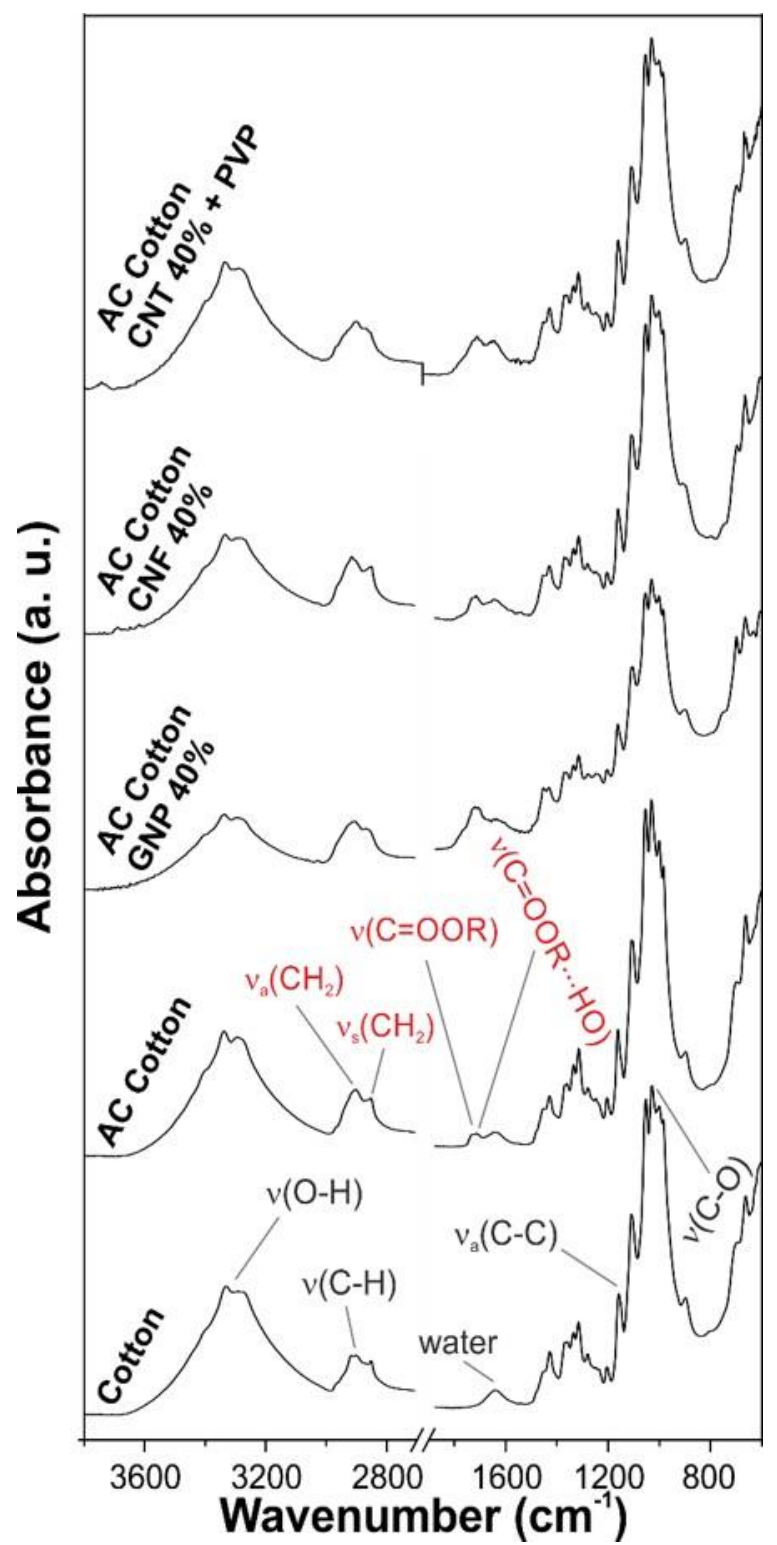

Figure S1. ATR-FTIR spectra of pure cotton, AC, GnPs $40 \%$, CnFs 40\%, and CnTs $40 \%$ in the $3800-600 \mathrm{~cm}^{-1}$ region. The main assignments for cotton (black), and polyaleuritate (red) are included.

Samples were chemically characterized by ATR-FTIR. Main peaks of pure cotton were ascribed to the chemical structure of cellulose: $\mathrm{OH}$ stretching mode at $3297 \mathrm{~cm}^{-1}, \mathrm{CH}$ stretching mode at $2883 \mathrm{~cm}^{-1}$, adsorbed water at $1642 \mathrm{~cm}^{-1}$, asymmetric C-C stretching mode at $1159 \mathrm{~cm}^{-1}$, and C-O stretching mode at 1028 $\mathrm{cm}^{-1} \cdot{ }^{1]}$ On the other hand, after the thermal treatment aleuritic acid was polymerized into polyaleuritate (a cutin-like polymer), revealing additional bands related to this polyester: asymmetric and symmetric $\mathrm{CH}_{2}$ stretching mode at $2903 \mathrm{~cm}^{-1}$ and $2831 \mathrm{~cm}^{-1}$, respectively, and $\mathrm{C}=\mathrm{O}$ stretching mode of free and $\mathrm{H}$-bond interacting ester groups at $1730 \mathrm{~cm}^{-1}$ and 1715 $\mathrm{cm}^{-1}$, respectively. This last band is associated with the formation of $\mathrm{H}$-bonds between the $\mathrm{OH}$ groups of cellulose and the hydroxyl and ester groups of polyaleuritate ${ }^{[1,2]}$ Interestingly, the presence of graphene, carbon nanofibers, carbon nanotubes, and PVP does not affect the infrared profile of the samples, indicating that polymerization of aleuritic acid is not influenced by these materials.

\section{Thermogravimetric Analysis}

The results regarding the thermogravimetric analysis of the pure cotton and of the polymerized aleuritic acid on cotton (AC) are displayed in Figure S2. The Figure shows the weight percent lost versus the temperature. No significant weight loss occurred until 


\section{WILEY-VCH}

approximately $250^{\circ} \mathrm{C}$ for all the samples. As such, it was possible to oven treat these samples at $190^{\circ} \mathrm{C}$ without experiencing any thermal degradation. Carbon nanomaterials are known for their thermal stability at temperature much higher than $190^{\circ} \mathrm{C}$ and therefore the sample containing these nanofillers are not degrading during the manufacturing process. ${ }^{[3]}$

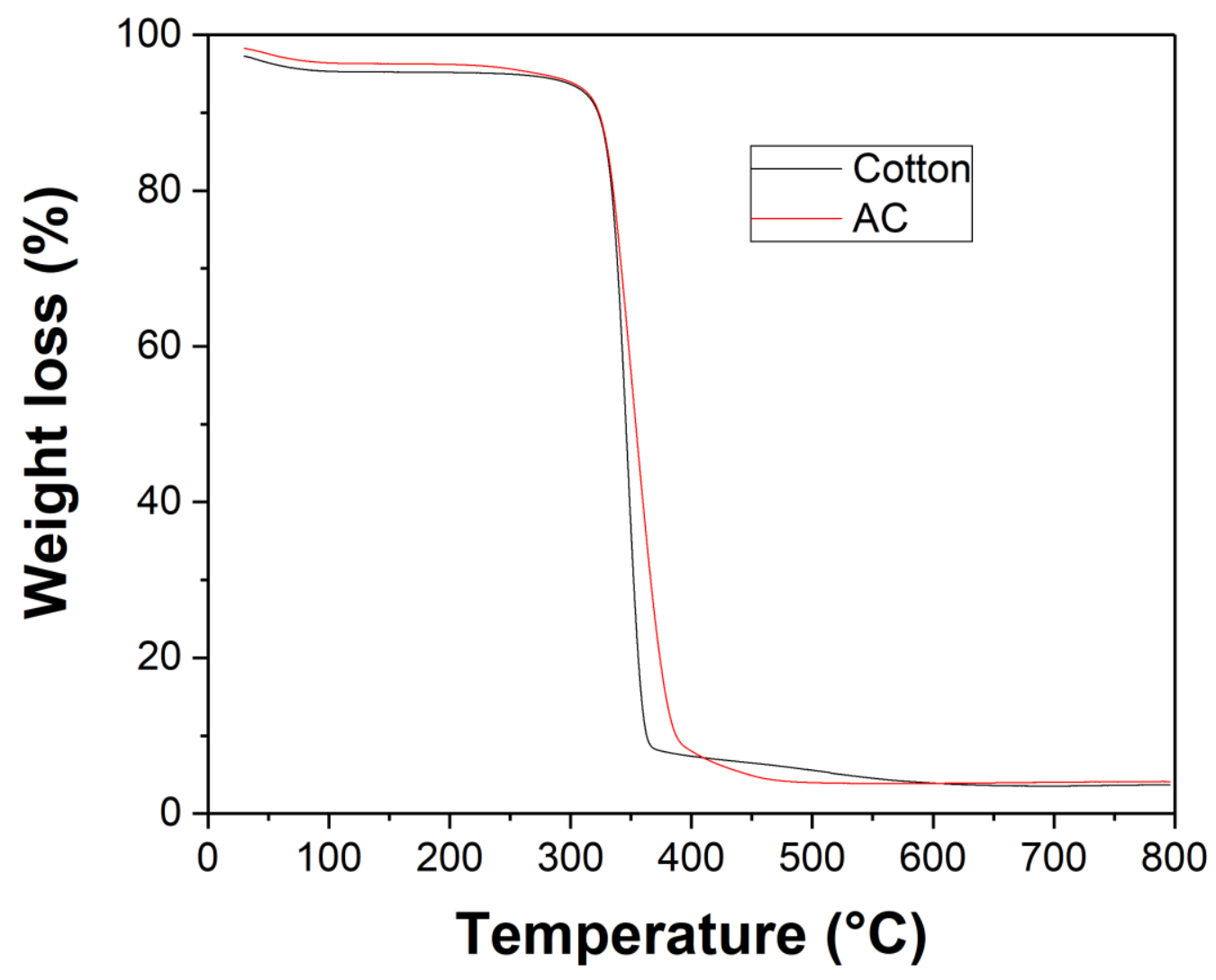

Figure S2. Thermogravimetric analysis of the pure cotton and of the AC sample.

Morphology of the cotton-based materials 


\section{WILEY-VCH}
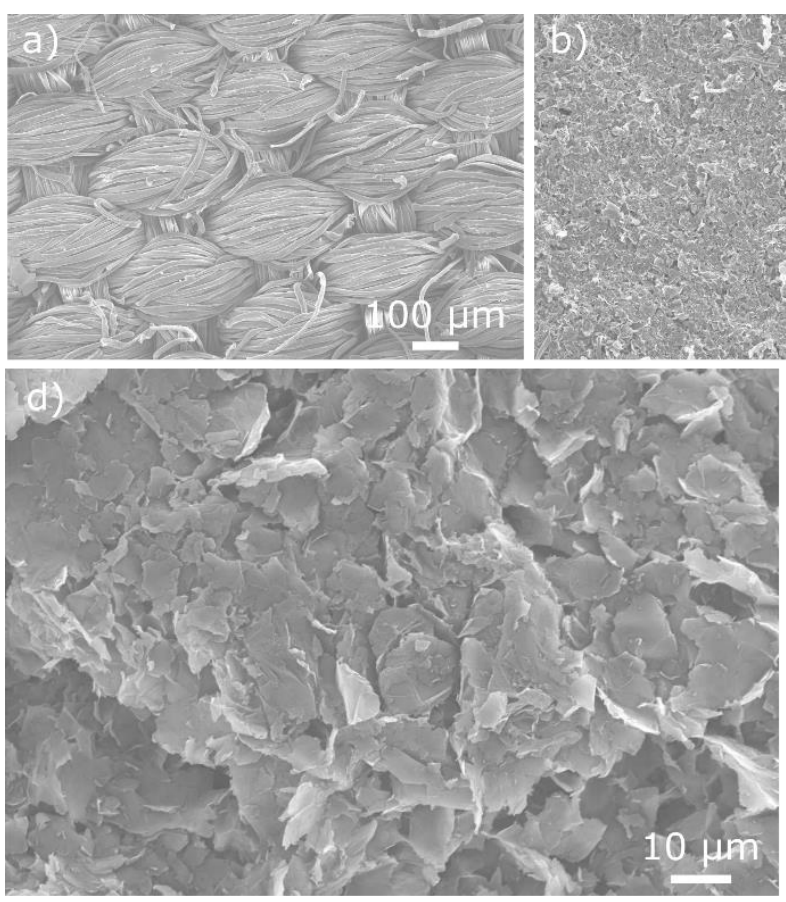
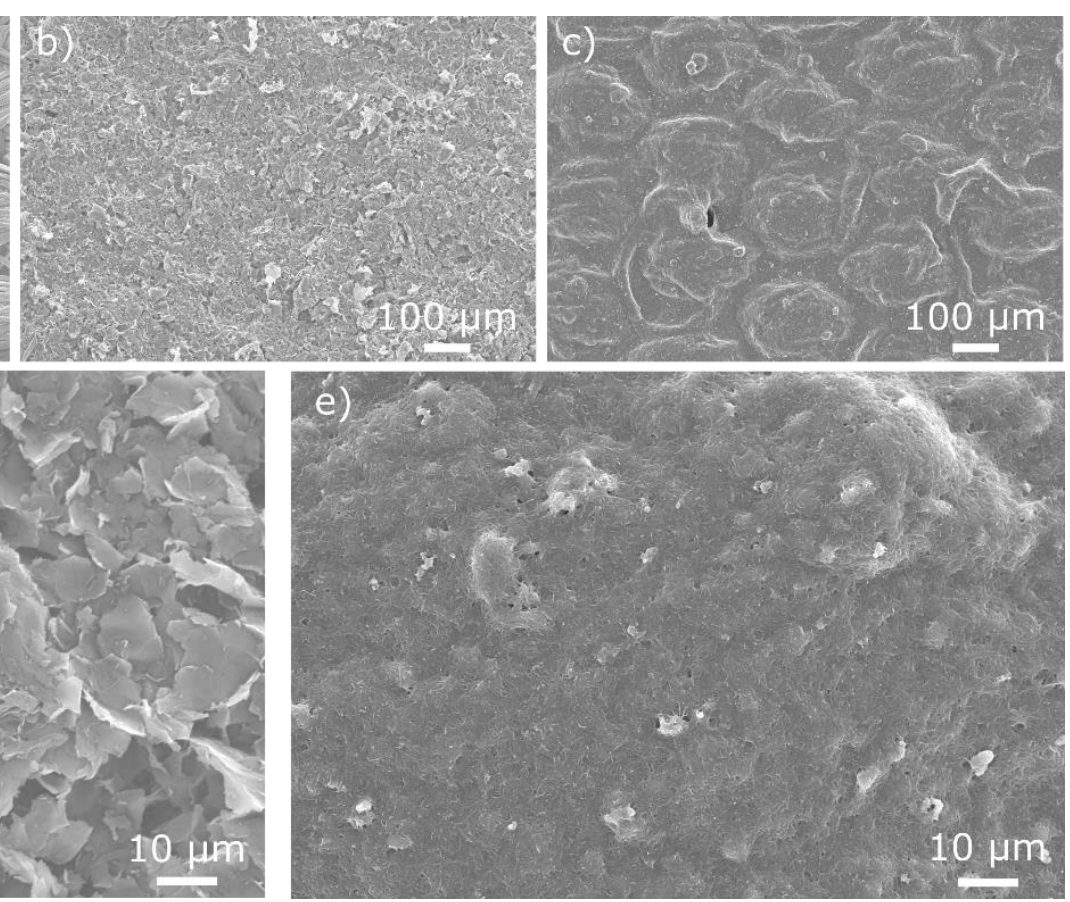

Figure S3. SEM images of the morphology of the materials for: (a) AC cotton, b) $40 \%$ GnPs and c) $50 \%$ CNT. d) and e) are high magnification SEM images of $40 \% \mathrm{GnPs}$ and $40 \% \mathrm{CnTs}$ sample, respectively.

\section{Cross section of the cotton-based materials}

Thickness values: a) $(10 \pm 3) \mu \mathrm{m}, \mathrm{b})(23 \pm 7) \mu \mathrm{m}, \mathrm{c})(19 \pm 5) \mu \mathrm{m}$.
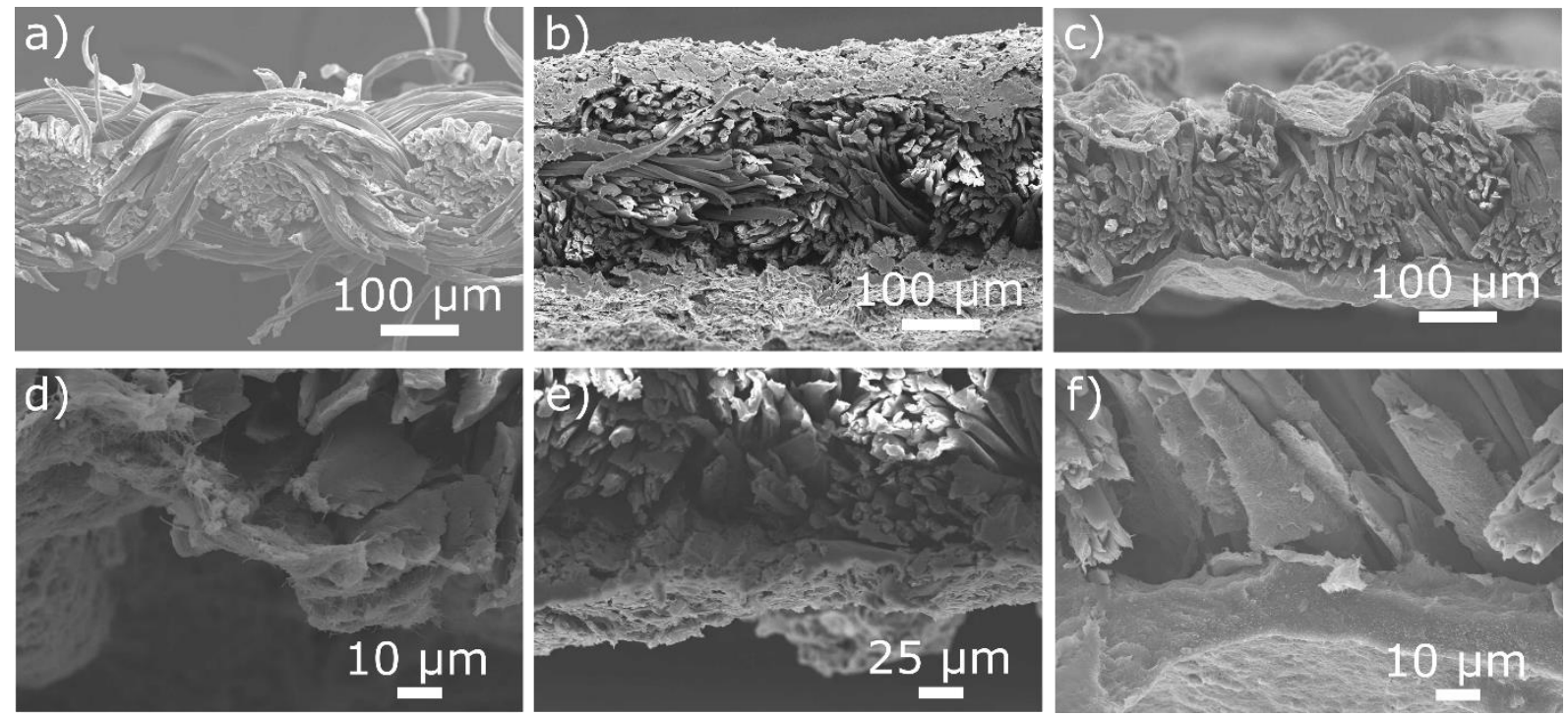

Figure S4. a), b) and c) are the cross section SEM image of AC cotton, $40 \%$ GnPs and 50\% CNT samples, respectively. d), e) and f) are details on the thicknesses of the layer of $40 \%$ CnFs, $40 \%$ GnPs and $40 \%$ CnTs samples, respectively. 


\section{WILEY-VCH}

\section{Biological Oxygen Demand}
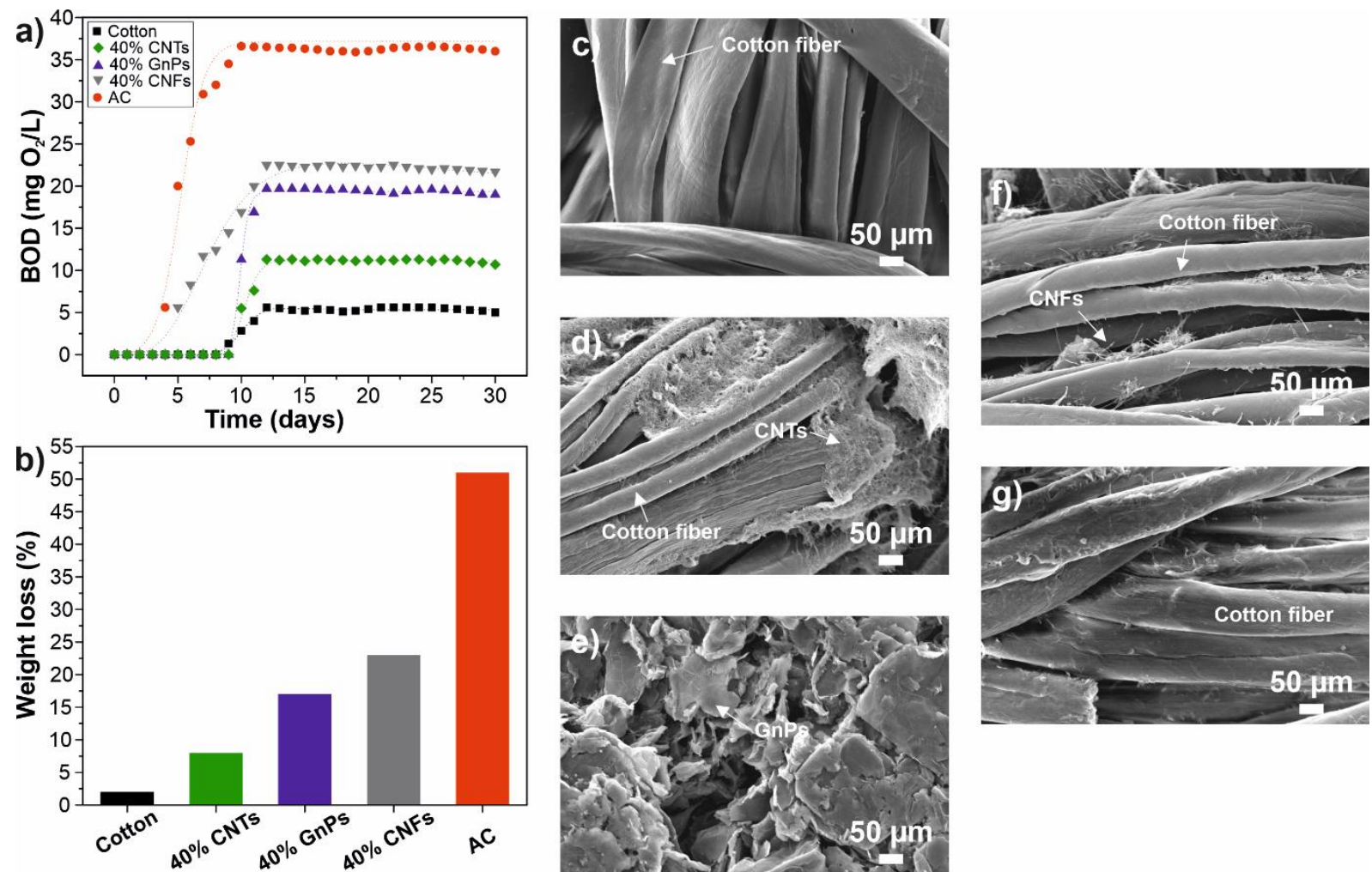

Figure S5. a) BOD data of cotton (black squares), $40 \%$ CnTs (grey triangles), $40 \% \mathrm{GnPs}$ (blue triangles), $40 \% \mathrm{CnFs}$ (green diamonds) and $\mathrm{AC}$ (red circles) biocomposites. b) Weight losses for the different samples after BOD test. c-g) SEM images of pure cotton, $40 \% \mathrm{CnTs}$, $40 \% \mathrm{GnPs}, 40 \% \mathrm{CnFs}$ and $\mathrm{AC}$, respectively.

\section{Mechanical properties}

Figure S6 displays the typical stress strain curves of the cotton-based materials. Pure cellulose sample is reported for comparison. The samples are labeled with numbers: sample number 1 is the fibrous cellulose network, sample number 2 is the $40 \% \mathrm{CNFs}$, sample number 3 is the AC specimen, sample number 4 is the $40 \%$ GNPs, sample number 5 is relative to the pure cotton and sample number 6 is the $40 \%$ CnTs. All the samples exhibited a stress-strain curve in between the pure cotton and the pure cellulose paper. Therefore all the samples are fullyflexible and bendable, as shown in figures S6b. A similar behavior was reported in a previous report. $^{[2]}$ 


\section{WILEY-VCH}
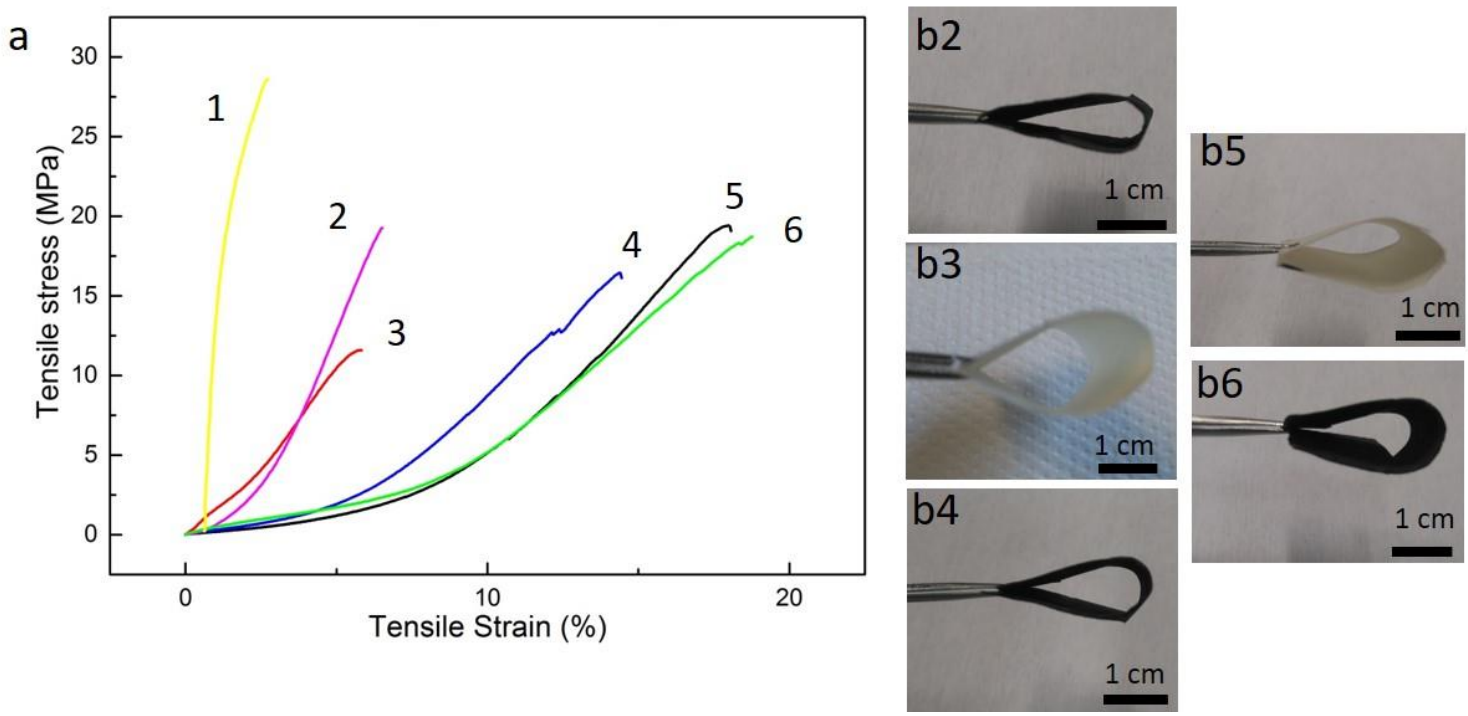

Figure S6. (a) Stress-strain curves and (b) images of the flexibility of the samples for: (1) pure cellulose paper; (2) 40\% CnFs; (3) AC cotton; (4) 40\% GnPs; (5) cotton; (6) 40\% CnTs.

\section{Washing Stability}

Maintaining effective electrical conductivity after laundry cycles is pivotal for wearable electronics applications. Therefore, the cotton nanocomposites were washed for 1 hour in water comprising a soap under stirring at $40{ }^{\circ} \mathrm{C}$ and their resistance was measured before and after such treatment. As seen in Figure S7, where the typical values of resistance obtained after washing are reported, the ratio $\mathrm{R} / \mathrm{R}_{0}$ vary very differently from sample to sample as a result of laundry cycles. In particular, the sample more stable to washing cycles are the $40 \%$ CnFs and the $40 \% \mathrm{CNFs}+20 \%$ PEDOT that increase the initial value of electrical resistance of the $30 \%$ and $70 \%$, respectively. The same sample with GnPs increase the resistance of $\approx$ 20000 and $\approx 12$ times, respectively. Finally, the $40 \%$ CnTs sample increase the resistance of 12 times after the washing cycles. As in the bending case, the more electrically stable samples after washing are the CnFs-based. 


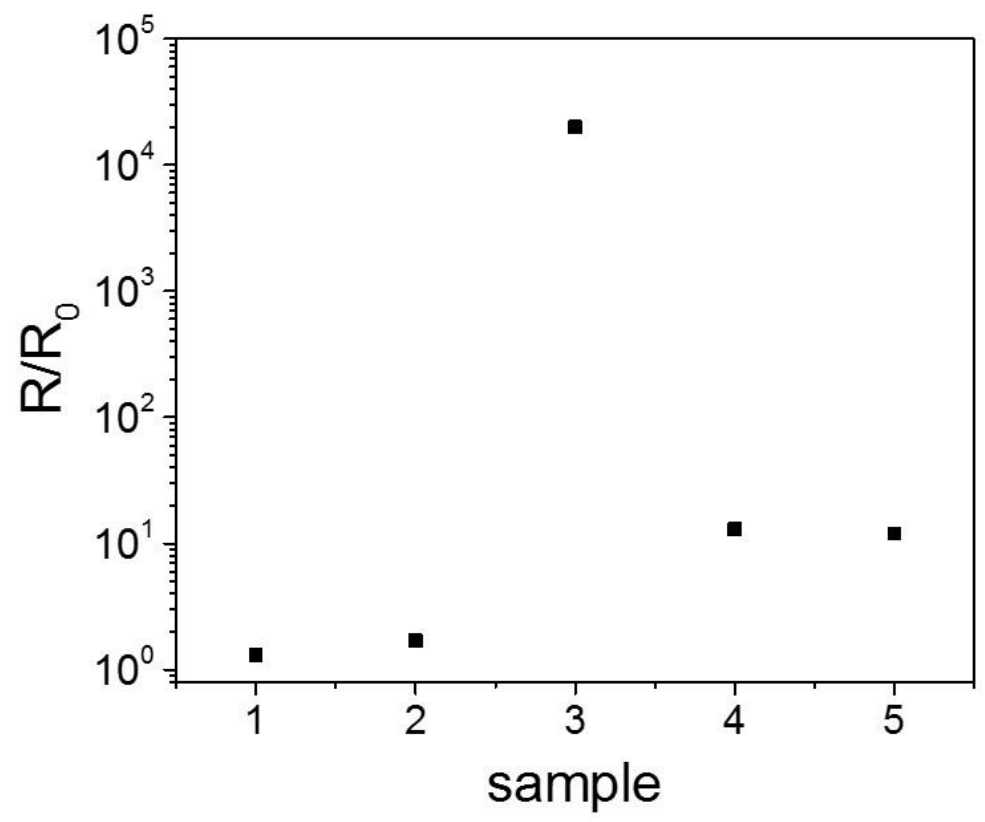

Figure S7. Variation of the electrical resistance of the samples after a washing cycle of 1 hour in water at $40^{\circ} \mathrm{C}$ with commercial soap. The investigated samples are: 1 (40\% CnFs), $2(40 \%$ CnFs + 20\% PEDOT), 3 (40\% GnPs), 4 (40\% GnPs + 20\% PEDOT), 5 (40\% CnTs).

\section{Thermal conductivity measurements}

To further characterize the fabricated materials, the in-plane thermal conductivity of the different biocomposites were studied by using infrared-camera imaging, and the obtained results are displayed in Figure S8a-d. To decrease the heat convection to the air, the backside of the samples was insulated by Teflon sheet by means of adhesive bonding and the samples were attached to a constant heat source with $130^{\circ} \mathrm{C}$ temperature at one edge, and the temperature propagation along the $x$-axis of the samples were followed during the time. As soon as the samples reached their steady-state condition (after $10 \mathrm{~min}$ ), the average temperature of the samples is estimated with standard deviations in different distances from the hotplate, namely as $x=0 \mathrm{~cm}, 0.3 \mathrm{~cm}, 0.6 \mathrm{~cm}, 0.9 \mathrm{~cm}, 1.2 \mathrm{~cm}$ and $1.5 \mathrm{~cm}$. In general, for any kinds of materials, at some distances from the hotplate, the temperature begins to decrease, even if the materials possess very high thermal conductivity. According to the thermographic images in Figure S8a-d, it can be observed that the temperature difference 


\section{WILEY-VCH}

between $x=0 \mathrm{~cm}$ and $x=1.5 \mathrm{~cm}$ in the sample AC cotton is higher than the other samples, which is related to the low thermal conductivity of this sample. However, introducing high thermally conductive fillers into the material, due to the better heat propagation in the sample, the temperature differences decreased. Moreover, the materials heat transfer with different thermal conductivities $(k=25 \mathrm{~W} / \mathrm{mK}, 50 \mathrm{~W} / \mathrm{mK}, 100 \mathrm{~W} / \mathrm{mK}, 200 \mathrm{~W} / \mathrm{mK}$ and $300 \mathrm{~W} / \mathrm{mK})$ was evaluated by a theoretical model ${ }^{[4]}$ (Equation 4$)$ and the obtained results were compared with the experimental data in order to estimate the in-plane thermal conductivity of the samples. The results are shown in Figure S8e.

$$
T-T_{a}=\frac{\left(T_{0}-T_{a}\right) \cosh [m(L-x)]}{\cosh (m L)}
$$

edge length of the sample, $x$ is the distance from hotplate with a constant temperature along the $x$-axis, $T$ is the current temperature of the sample along the $x$-axis, $T_{0}$ is the hotplate temperature and $T_{a}$ is the ambient temperature $\left(300^{\circ} \mathrm{K}\right)$. By inserting different parameters in the equation, the average temperature $(T)$ of the sample in different distances from hotplate can be calculated ${ }^{[119]}$ and the heat transfer profiles are shown in graph as solid lines and compared with the experimental ones in dots with errorbars (Figure S8e). For instance, by inserting $k=100 \mathrm{~W} / \mathrm{mK}$ and $200 \mathrm{~W} / \mathrm{mK}$ in the equation, and obtaining the 2-dimensional thermal conductivity, and fitting the average temperatures of the samples AC cotton with $40 \%$ $\mathrm{CnFs}, 40 \% \mathrm{GnPs}$ and $40 \% \mathrm{CnTs}$, these samples can have in-plane thermal conductivity around $150 \mathrm{~W} / \mathrm{mK}$, however, the in-plane thermal conductivity of AC sample is estimated around $40 \mathrm{~W} / \mathrm{mK}$. This differences could be attributed to the presence of nanofillers network connections inside the materials, which can improve the final heat conduction of the samples. 
WILEY-VCH
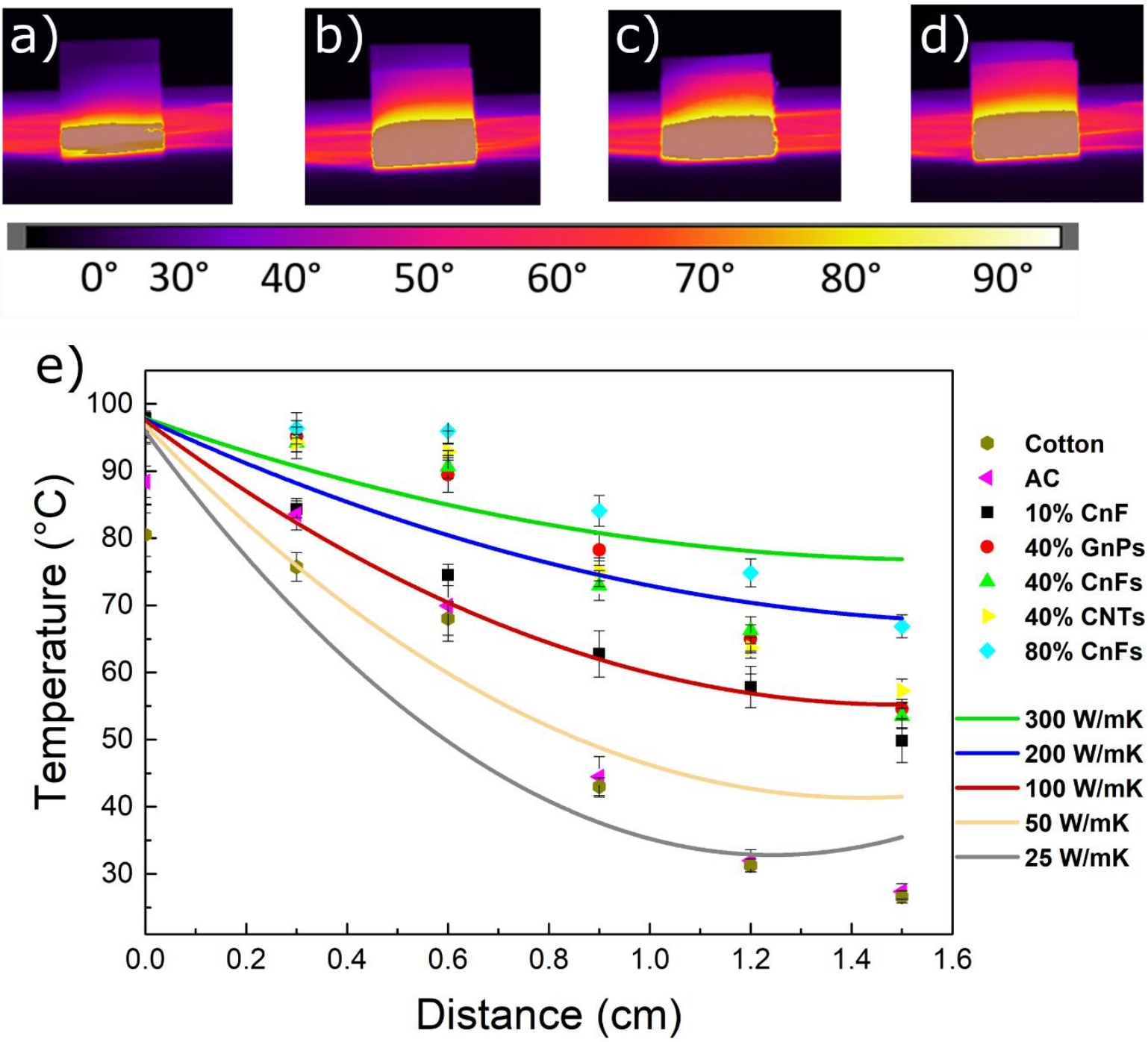

Figure S8. a), b), c) and d) are images recorded after 10 minutes with IR camera of AC, $40 \%$ GnPs, $40 \%$ CnFs and 40\% CnTs sample, respectively. e) Recorded temperature as a function of distance for the different samples and the calculated curves using equation (4).

Table S1. Reported measured values at room temperature of the TE properties of polyaleuritate-cotton composites with different percentages of CnFs, GnPs, and CnTs:PVP. In the first column the investigated materials are described (Samples), in the second one the abbreviation used in the text for each sample are shown (Label), and in the third and fourth the Seebeck coefficient $(\alpha)$ and sheet resistance $\left(R_{S}\right)$ are displayed, respectively.

\begin{tabular}{|c|c|c|c|}
\hline Samples & Label & $\alpha\left[\mu \mathrm{V} \mathrm{K}^{-1}\right]$ & $\mathrm{R}_{S}\left[\Omega \square^{-1}\right]$ \\
\hline AC cotton and $10 \% \mathrm{CnFs}$ & $10 \% \mathrm{CnFs}$ & $6.9 \pm 0.3$ & $(0.7 \pm 0.1)^{*} 10^{3}$ \\
\hline AC cotton and $80 \% \mathrm{CnFs}$ & $80 \% \mathrm{CnFs}$ & $6.5 \pm 0.8$ & $51 \pm 7$ \\
\hline $\begin{array}{l}\text { AC cotton and } 40 \% \text { CnFs } \\
+20 \% \text { PEDOT:PSS }\end{array}$ & $\begin{array}{c}40 \% \text { CnFs } \\
+20 \% \\
\text { PEDOT }\end{array}$ & $8.0 \pm 0.4$ & $24 \pm 3$ \\
\hline
\end{tabular}




$\begin{array}{cccc}\text { AC cotton and 10\% GnPs } & 10 \% \text { GnPs } & 14.8 \pm 0.4 & (4.4 \pm 0.6)^{*} 10^{3} \\ \text { AC cotton and } 80 \% \text { GnPs } & 80 \% \text { GnPs } & 14 \pm 2 & (0.13 \pm 0.02)^{*} 10^{3} \\ \begin{array}{c}\text { AC cotton and 40\% GnPs } \\ +20 \% \text { PEDOT:PSS }\end{array} & \begin{array}{c}40 \% \text { GnPs } \\ +20 \%\end{array} & 16 \pm 2 & 80 \pm 11 \\ \text { PEDOT } & & \\ \text { AC cotton and 40\% } & 20 \% \text { CnTs } & -3.0 \pm 0.9 & 80 \pm 11 \\ \text { CnTs:PVP (20:80) } & \text { 80\% CnTs } & -3.0 \pm 0.8 & 8.5 \pm 1.2 \\ \text { AC cotton and 40\% } & \text { CnTs:PVP (20:80) } & & \end{array}$

\section{Supporting information References:}

[1] J. A. Heredia - Guerrero, J. J. Benítez, P. Cataldi, U. C. Paul, M. Contardi, R. Cingolani, I. S. Bayer, A. Heredia, A. Athanassiou, Advanced Sustainable Systems 2017, 1, 1600024. [2] P. Cataldi, J. A. Heredia - Guerrero, S. Guzman - Puyol, L. Ceseracciu, L. La Notte, A. Reale, J. Ren, Y. Zhang, L. Liu, M. Miscuglio, P. Savi, S. Piazza, M. Duocastella, G. Perotto, A. Athanassiou, I. S. Bayer, Advanced Sustainable Systems 2018, 1800069.

[3] P. Cataldi, F. Bonaccorso, A. Esau del Rio Castillo, V. Pellegrini, Z. Jiang, L. Liu, N. Boccardo, M. Canepa, R. Cingolani, A. Athanassiou, Advanced Electronic Materials 2016, 2, 1600245.

[4] M. Zahid, M. Masood, A. Athanassiou, I.S. Bayer, Applied Physics Letters 2018, 044103. 